\title{
Inhibition of sphingosine kinase 2 down-regulates ERK/c-Myc pathway and reduces cell proliferation in human epithelial ovarian cancer
}

\author{
Lan Dai ${ }^{1,2}$, Wenjing Wang ${ }^{1,2}$, Yixuan Liu ${ }^{1,2}$, Keqi Song ${ }^{1,2}$, Wen Di $^{1,2,3}$ \\ ${ }^{1}$ Department of Obstetrics and Gynecology, Ren Ji Hospital, School of Medicine, Shanghai Jiao Tong University, Shanghai, China; ${ }^{2}$ Shanghai Key \\ Laboratory of Gynecologic Oncology, Ren Ji Hospital, School of Medicine, Shanghai Jiao Tong University, Shanghai, China; ${ }^{3}$ State Key Laboratory \\ of Oncogene and Related Genes, Shanghai Cancer Institute, Ren Ji Hospital, School of Medicine, Shanghai Jiao Tong University, Shanghai, China \\ Contributions: (I) Conception and design: W Di, L Dai, K Song; (II) Administrative support: W Di, L Dai; (III) Provision of study materials or \\ patients: K Song, W Wang, Y Liu; (IV) Collection and assembly of data: L Dai, K Song, W Wang, Y Liu; (V) Data analysis and interpretation: L \\ Dai, K Song, W Wang, Y Liu; (VI) Manuscript writing: All authors; (VII) Final approval of manuscript: All authors. \\ Correspondence to: Wen Di; Lan Dai; Keqi Song. Department of Obstetrics and Gynecology, Ren Ji Hospital, School of Medicine, Shanghai Jiao Tong \\ University, Shanghai 200127, China. Email: diwen163@163.com; delta496@163.com; songkeqi@163.com.
}

Background: Epithelial ovarian cancer (EOC) is the leading cause of death from female cancers. In our previous study, sphingosine kinase 2 (SphK2) inhibitor was shown to display anti-EOC activities. The purpose of this study was to evaluate further the expression characteristics and clinical significance of SphK2 in EOC and to explore the roles and underlying mechanisms of SphK2 in EOC cell survival.

Methods: The expression of SphK2 was examined by immunohistochemistry (IHC) and Western blot, and its clinical implications and prognostic significance were analyzed. We performed a cellular proliferation assay, and a mouse xenograft model was established to confirm the roles of SphK2 in vitro and in vivo. Cell cycle analysis, apoptosis assay, and Western blot were performed to examine cell cycle progression and apoptosis rate. Gene set enrichment analysis (GSEA), and Western blot were used to investigate the downstream signaling pathways related to SphK2 function.

Results: The expression level of SphK2 was shown to be associated with stage, histological grade, lymph node metastasis, and ascites status. More importantly, a high SphK2 expression level was a prognostic indicator of overall survival (OS) and relapse-free survival (RFS). Moreover, knockdown of SphK2 arrested cell cycle progression and inhibited EOC cell proliferation both in vitro and in vivo. Furthermore, ERK/ c-Myc, the key pathway in EOC progression, was important for SphK2-mediated mitogenic action in EOC cells.

Conclusions: Our findings provided the first evidence that SphK2 played a crucial role in EOC proliferation by regulating the ERK/c-Myc pathway. This indicated that SphK2 might serve as a prognostic marker and potential therapeutic target in EOC.

Keywords: Epithelial ovarian cancer (EOC); sphingosine kinase 2 (SphK2); extracellular signal-regulated kinase (ERK); c-Myc; proliferation

Submitted Oct 04, 2020. Accepted for publication Jan 17, 2021.

doi: $10.21037 / \mathrm{atm}-20-6742$

View this article at: http://dx.doi.org/10.21037/atm-20-6742 


\section{Introduction}

Epithelial ovarian cancer (EOC), the most lethal gynecologic malignancy, is the leading cause of death from female cancers (1). The majority of EOC patients are first diagnosed at late stages because the early-stage disease is virtually asymptomatic, which causes significantly poor prognosis and high mortality (2). Surgery combined with platinum/taxane chemotherapy represents the first-line treatment for EOC. Unfortunately, most patients, who initially respond to this treatment, eventually develop chemoresistance (3). Thus, the development of a novel therapeutic strategy is needed. Unlike traditional cytotoxic chemotherapy, targeted therapy inhibits cancer growth by interfering with specific molecules needed for cancer progression, which may become a new hope for EOC therapy $(4,5)$. Understanding the underlining molecular mechanisms associated with EOC progression is therefore critical to identify new targets for new targeted therapy.

The roles of sphingolipids in cell biology and cell fate have been explored for several decades. There is accumulating evidence demonstrating that disturbed sphingolipid metabolism may contribute to cancer initiation and progression and present an exploitable target for cancer therapy (6). Sphingosine kinases (SphKs), ceramide, sphingosine, transmembrane transporters, sphingosine-1phosphate (S1P), and $\mathrm{S} 1 \mathrm{P}$ receptors (S1PRs) are the key players in the sphingolipid metabolic pathway. The "insideout" model is widely used to explain the function of SphK/ $\mathrm{S} 1 \mathrm{P} / \mathrm{S} 1 \mathrm{PR}$ signaling (7). It is proposed that $\mathrm{S} 1 \mathrm{P}$, generated by SphK, can be secreted into the extracellular milieu and then activates S1PRs through autocrine and paracrine manners, leading to the activation of downstream signals. Moreover, S1P can also function intracellularly independent of S1PRs (8). Among the key players of the sphingolipid metabolic pathway, much attention has been paid to SphKs because their catalytic activity lies at the critical juncture in regulating sphingolipid metabolism. The SphKs exhibit 2 isoforms, SphK1 and SphK2, of which SphK1 has emerged as an important and critical signaling enzyme because it is involved in many aspects of cancer progression, such as proliferation, angiogenesis, metastasis, and chemoresistance (9-11). Consistent with this, we found previously that the expression level of SphK1 was significantly increased in EOC tissues and was associated with EOC metastasis and angiogenesis $(12,13)$. Although the two isoforms of SphKs (SphK1 and SphK2) share high sequence similarity, they differ significantly in distribution, regulation, and function.
The role of SphK2 in cell survival is controversial, and both pro-apoptotic and pro-proliferative functions have been suggested. Initially, SphK2 was recognized as a proapoptotic protein because SphK2 over-expression inhibited the growth and promoted cancer cells' apoptosis $(14,15)$. However, it was subsequently found to be pro-survival as SphK2 down-regulation or inhibition suppressed tumor cells' growth (16-18). Recent work has suggested that SphK2 plays a role in promoting cancer by regulating several important pro-oncogenic pathways, such as protein kinase B (AKT), extracellular signal-regulated kinase (ERK), and signal transducer and activator of transcription-3 (STAT3) pathways $(19,20)$. Moreover, SphK2 could also work as an epigenetic regulator. For example, SphK2 was reported to enhance MYC expression, an important oncogene, via regulation of histone deacetylase 1/2 (HDAC1/2) (21). Until now, much is still unknown or controversial about SphK2.

Our research group recently found that treatment with an orally active and specific SphK2 inhibitor, ABC294640, significantly inhibited EOC cell proliferation and increased apoptosis (22). This result suggested SphK2 might be a potential target for EOC therapy. However, there is no available data on SphK2 expression patterns in EOC tissues and their clinical significance. Moreover, the molecular mechanisms of SphK2 in EOC growth remain largely unknown. This study aimed to evaluate the expression characteristics and clinical significance of SphK2 in EOC and explore the roles and underlying mechanisms of SphK2 in EOC cell survival through both in vitro and in vivo studies.

We present the following article in accordance with the ARRIVE reporting checklist (available at http://dx.doi. org/10.21037/atm-20-6742).

\section{Methods}

\section{Reagents and antibodies}

Antibodies against SphK2 (Abcam, ab264042, rabbit), c-Myc (Abcam, ab32072, rabbit), and glyceraldehyde 3-phosphate dehydrogenase (GAPDH) (Abcam, ab8245, mouse) were purchased from Abcam (Cambridge, MA, USA). Antibodies against ERK1/2 (CST, 4696, rabbit), phosphor-ERK1 (Thr202/Tyr204)/ERK2 (Thr185/Tyr187) (CST, 4370, rabbit), cyclin D1 (CST, 2978, rabbit), phosphor-Rb (CST, 8516, rabbit) were purchased from Cell Signaling Technology (Danvers, MA, USA). The inhibitor U0126 (Sigma, 662005) was ordered from Sigma-Aldrich (St. Louis, MO, USA). 


\section{Tissue specimens}

Tissue specimens were collected from the patients without preoperative chemotherapy, including 5 normal ovarian tissues and 50 primary epithelial ovarian cancer (PEOC) tissues (stages I-II 20 cases, stages III-IV 30 cases). All procedures performed in this study involving human participants followed the Declaration of Helsinki (as revised in 2013). The institutional ethical committee approved this study of Renji Hospital (RA2019-076), and all the participants provided informed consent.

\section{Cell lines and culture conditions}

Human EOC cell lines SKOV3 and OVCAR3 were obtained from American Type Culture Collection (ATCC). The SKOV3 cell line was routinely cultured in Dulbecco's Modified Eagle Medium (DMEM) (12430054, Invitrogen, Carlsbad, CA, USA) supplemented with $10 \%$ fetal bovine serum (FBS, Invitrogen, 16140071) and 1\% antibiotics. The OVCAR3 cell line was routinely cultured in Roswell Park Memorial Institute-1640 (RPMI-1640) medium (Invitrogen, A1049101) supplemented with $20 \% \mathrm{FBS}, 0.01 \mathrm{mg} / \mathrm{mL}$ insulin (SigmaAldrich, I0908), and 1\% antibiotics. The A2780 was purchased from the China Center for Type Culture Collection (CCTCC) and routinely cultured in DMEM supplemented with $10 \%$ FBS and $1 \%$ antibiotics. The immortalized ovarian surface epithelial (IOSE) cell line was a gift from Prof. MW-Y Chan (National Chung Cheng University, Taiwan) and cultured in DMEM supplemented with $10 \%$ FBS and $1 \%$ antibiotics.

\section{Immunobistochemistry}

Immunostaining was performed and scored as previously described (12). The primary antibody used was anti-SphK2 (1:100, Abcam). The immunostaining intensity was scored as follows: negative [0], weak [1], moderate [2], and strong [3]. The proportion of positively stained tumor cells was assessed as follows: no positive tumor cells [0], $<25 \%$ [1], 26-50\% [2], 50-75\% [3], and >75\% [4]. Staining index (SI) was calculated as staining intensity score $\times$ proportion score. The protein expression level was considered to be high when the score was $>3$ and low when the score was $\leq 3$.

\section{Western blot analysis}

Western blotting was performed as previously described (23). Briefly, cells were harvested after the indicated treatments and lysed with radioimmunoprecipitation assay (RIPA) buffer plus protease inhibitors. The protein was quantified and resolved by $8-10 \%$ sodium dodecyl sulfate-polyacrylamide gel electrophoresis (SDS-PAGE) and transferred to polyvinylidene fluoride (PVDF) membranes. The membranes were then incubated with appropriate antibodies according to the manufacturer's standard methods. Finally, the proteins were visualized using an enhanced chemiluminescence detection kit (32109; Pierce, Lambertville, MI, USA).

\section{Transient [small interfering RNA (siRNA)] and stable [short bairpin RNA (shRNA)] transfection}

The siRNAs specifically targeting human ERK1 (5'-CAUGAAGGCCCGAAACUACUU-3'), ERK2 ( 5 ' - GCGCUUCAGACAUGAGAACUU-3 '), and the scrambled control siR A ( 5 '-AAUUCUCCGAACGUGUCACGU-3') were synthesized by GenePharma (Shanghai, China). The siRNA duplexes were transfected using Lipofectamine (Invitrogen) according to the manufacturer's protocol. The shRNA lentiviral packaging plasmid specifically targeting human SphK2 (5'-AACCUCAUCCAGACAGAACGA-3') and the non-targeting negative control plasmid ( 5 ' -AAUUCUCCGAACGUGUCACGU-3') were constructed by GenePharma. Cell lines were transduced with lentiviral vectors at a multiplicity of infection $(\mathrm{MOI})=5$. To establish the cells stably down-regulating SphK2, transfected cells were selected by culturing in puromycin. Single colonies of stable transfectants were isolated and expanded. Several independent clones were used to complete the experiment to avoid errors caused by the clonal effect.

\section{Real-time RT-PCR}

The RNA was extracted by TRIzol Reagent (Thermo Fisher, Waltham, MA, USA). The messenger RNA (mRNA) levels were measured by Synergy Brands, Inc. (SYBR) Green reverse transcription polymerase chain reaction (RT-PCR) and then calculated by $2^{-\Delta \Delta \mathrm{Ct}}$ method. Primers were as follows: SphK2, 5'-GGTTGCTTCTATTGGTCAATCC-3' (forward) and 5'-GTTCTGTCGTTCTGTCTGGATG-3' (reverse); GAPDH, 5'-TGCACCACCAACTGCTTAGC-3' (forward) and 5'-GGCATGGACTGTGGTCATGAG-3' (reverse) (23).

\section{Cellular proliferation assay}

Cell proliferation was assessed using WST-1 (11644807001; 
Roche, Basel, Switzerland) assay as previously described (24). Briefly, the indicated cells were seeded into 96-well plates, and the cell number was measured at 24, 48, 72, and $96 \mathrm{~h}$. At each time point, WST-1 assay reagent was added into each well and cultured at $37^{\circ} \mathrm{C}$ for $2 \mathrm{~h}$. The supernatant from each well was then collected for measurement of absorbance at $450 \mathrm{~nm}$. There was a direct correlation between the cell number and the absorbance at $450 \mathrm{~nm}$ in the current study.

\section{Animal studies}

All animal experiments were carried out following the National Institutes of Health (NIH) Guide for the Care and Use of Laboratory Animals 2018 and approved by Shanghai Jiao Tong University School of Medicine. The experimental protocols were approved by the Institutional Animal Care and Use Committee of Shanghai Jiao Tong University School of Medicine (A2018021). Mice were purchased from the Chinese Academy of Sciences. The mice were housed in a climate-controlled facility with free access to food and water. The animals' environment was a $12 \mathrm{~h} \mathrm{light/dark}$ cycle with a constant temperature of $22 \pm 1{ }^{\circ} \mathrm{C}$ and humidity of $55 \% \pm 5 \%$. To establish subcutaneous transplantation models, female BALB/c nu/nu mice aged 5-6 weeks ( 8 mice in each group) were subcutaneously injected with $2 \times 10^{6}$ EOC cells stably transfected with indicated plasmids. Tumor volumes were calculated twice a week using the following formula: $\mathrm{V}=$ (largest diameter $\times$ small diameter $\times$ depth $) \times \pi / 6$. The mice were sacrificed 28 days after injection of EOC cells, and the weight of tumors was measured.

\section{Cell cycle analysis}

Cells were trypsinized, and $1 \times 10^{6}$ cells were used for analysis. Cells were fixed in 70\% ice-cold ethanol overnight and stained with propidium iodide at room temperature for $45 \mathrm{~min}$. The cellular DNA content was analyzed by flow cytometry.

\section{Apoptosis assay}

Cells were harvested, and $1 \times 10^{6}$ cells were used for analysis. The annexin V-FITC/PI apoptosis detection kit [556547; BD Biosciences, San Jose, CA, USA)] was used to identify apoptotic cells by flow cytometry following the manufacturer's instructions.

\section{Microarray analysis}

Tumor RNA was prepared with RNeasy Plus Mini Kit (74134; Qiagen, Hilden, Germany) according to the manufacturer's protocol. Total RNA was subjected to microarray analysis with Whole Human Genome Oligo Microarray (Agilent, Santa Clara, CA, USA).

\section{Statistical analysis}

Statistical analyses were performed by using the SPSS software (IBM, Chicago, IL, USA). The $\chi^{2}$ test was used to analyze the correlations between SphK2 expression and the clinicopathologic features of EOC (20,25). Kaplan-Meier curves and log-rank tests were used to analyze the survival data. Each experiment was performed independently in triplicate in our research. The values were presented as the mean \pm standard deviation (SD) and were analyzed by $t$-test. A P value less than 0.05 was considered significant.

\section{Results}

\section{SphK2 expression patterns in primary EOC tissues}

The SphK2 protein expression was examined in 50 PEOC and 5 normal ovarian tissue specimens by immunohistochemical (IHC) staining. Representative photographs of SphK2 immunostaining are shown in Figure 1A. High SphK2 expression was shown in 62\% [31/50] of the PEOC specimens and $38 \%$ [19/50] showed low expression. In contrast, none of the normal ovarian tissue specimens exhibited high SphK2 expression. As a negative control, normal rabbit immunoglobulins were substituted for primary antibodies (Figure S1A). The IHC staining of SphK2 in human breast cancer tissue, which is SphK2 positive, was used as a positive control (Figure S1B). Consistent with the findings from tissue specimens, the expression of SphK2 was significantly elevated in all 4 EOC cell lines examined compared to IOSE cells, an immortalized non-tumorigenic human ovarian surface epithelial cell line (Figure 1B). We further examined the relationship between SphK2 expression levels in PEOC and clinic-pathological characteristics (Table 1). High SphK2 expression level was associated with higher International Federation of Obstetrics and Gynecology (FIGO) stage $(\mathrm{P}=0.001)$, higher histological grade $(\mathrm{P}=0.049)$, lymph node metastasis $(\mathrm{P}=0.001)$, and ascites $(\mathrm{P}=0.012)$, which indicated that $\mathrm{SphK} 2$ expression was linked to the oncogenic behavior of EOC. However, we observed no correlation between SphK2 levels and age and histologic subtypes. 
A

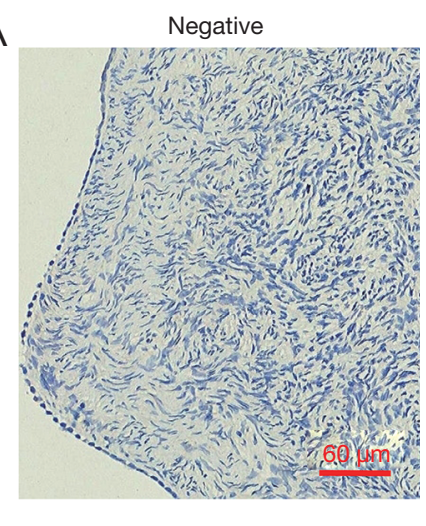

Normal ovary

B

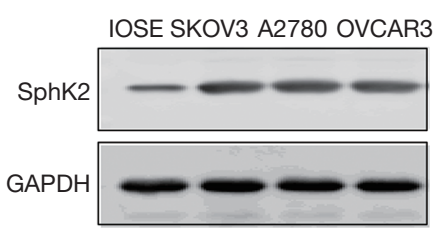

C

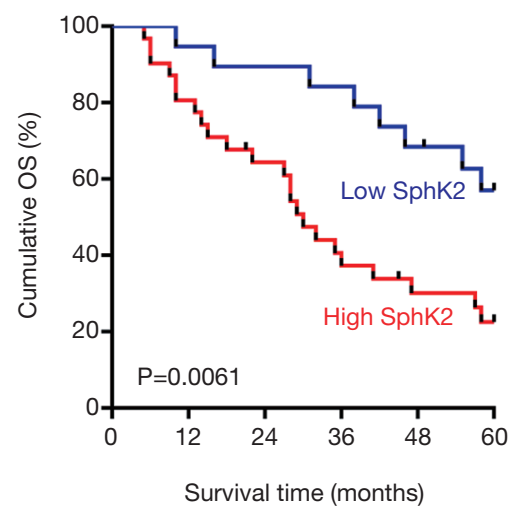

Low

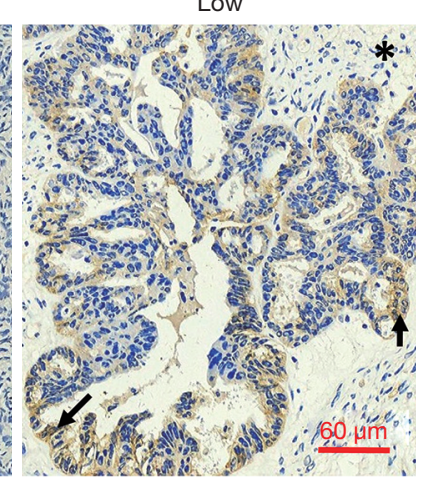

High

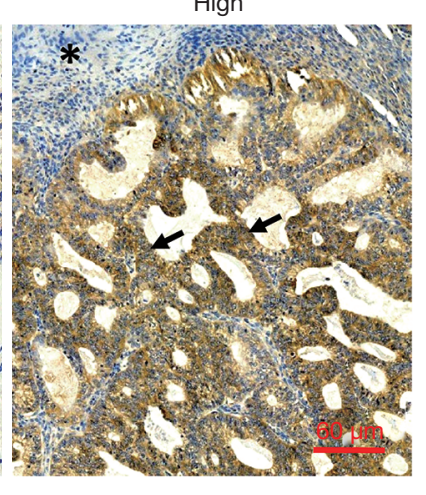

Ovarian cancer

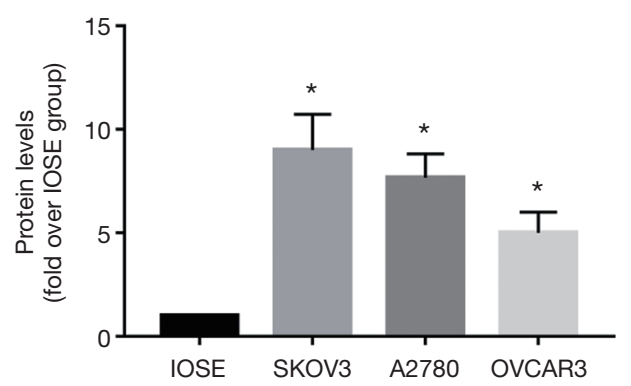

$\mathrm{D}$

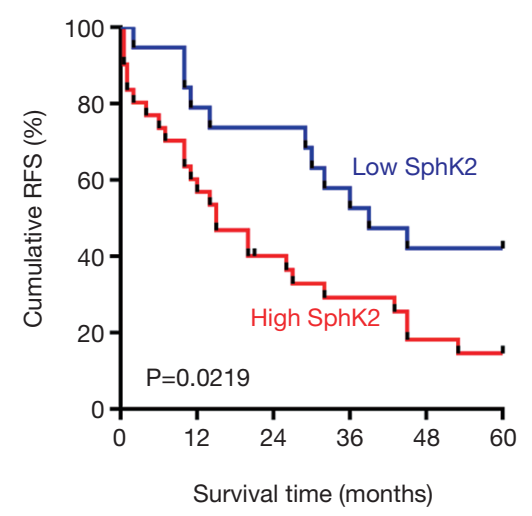

Figure 1 SphK2 over-expression in human ovarian cancer and its prognostic significance. (A) IHC staining of SphK2 in normal ovary and serous ovarian cancer tissues. The scale bar represents $60 \mu \mathrm{m}$. Ovarian cancer tissue containing malignant cells, which are SphK2 positive (arrow), and SphK2 negative adjacent stroma (star). (B) Western blot analysis of SphK2 in IOSE cell line and ovarian cancer cell lines. (C,D) Kaplan-Meier curves showing OS and RFS of ovarian cancer patients. Curves show low (blue line, 19 cases of ovarian cancer patients) and high SphK2 protein expression (red line, 31 cases of ovarian cancer patients). The experiments were repeated 3 times. *, $\mathrm{P}<0.05$. SphK2, sphingosine kinase 2; IHC, immunohistochemical; IOSE, immortalized ovarian surface epithelial; OS, overall survival; RFS, relapse-free survival 
Table 1 Clinicopathological features of ovarian tissue with regard to the relative expression of SphK2

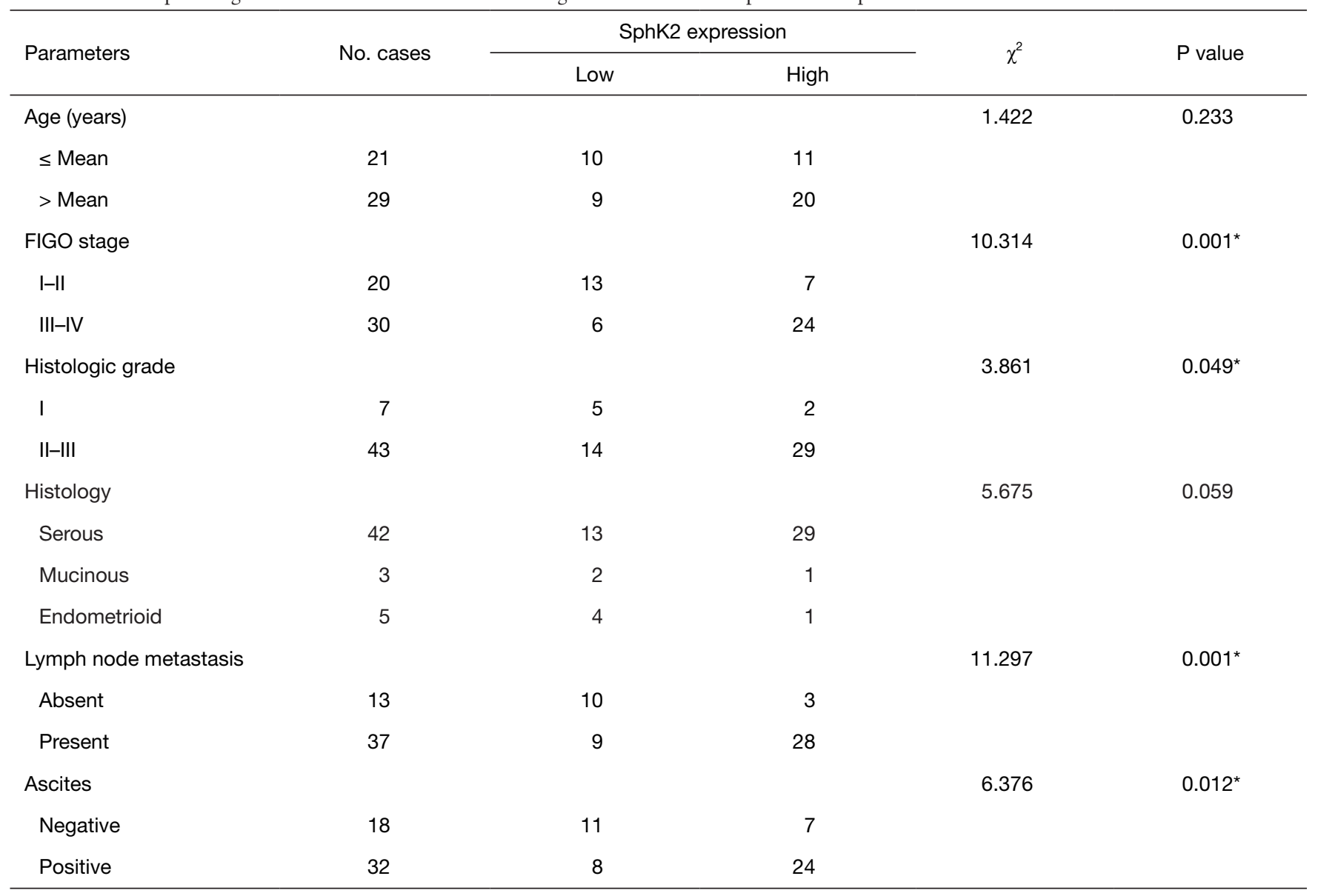

* $\mathrm{P}<0.05$. SphK2, sphingosine kinase 2; FIGO, International Federation of Gynecology and Obstetrics.

\section{Correlations between SpbK2 expression level and survival analysis}

The prognostic value of SphK2 was analyzed by comparing the overall survival (OS) and relapse-free survival (RFS) of patients with high and low SphK2 expression. Kaplan-Meier analysis showed that patients with high SphK2 expression had a significantly lower postoperative 5 -year OS and a significantly lower postoperative RFS than those with low SphK2 expression (Figure 1C,D) $(\mathrm{P}<0.01)$. Together, these data suggested that $\mathrm{SphK} 2$ was a potentially useful predictor for the outcome of EOC.

\section{SphK2 is required for EOC cell growth in vitro and in vivo}

To assess the importance of SphK2 in EOC cells, we performed shRNA-based knockdown experiments in human EOC cell lines, which resulted in an efficient reduction in SphK2 mRNA and protein levels compared to the control cells transfected with a negative control vector (Figure $2 A, B$ ). Proliferation assays revealed that SKOV3 cells subjected to SphK2 knockdown by shRNA were strongly inhibited in cell growth compared to controls (Figure 2C). To investigate whether SphK2 also has a role in EOC progression, we used a subcutaneous transplanted model of ovarian cancer in nude mice ( 8 mice in each group). The mice were subcutaneously injected with SphK2downregulated SKOV3 cells or control cells, and tumor growth was measured after 1 month. As shown in Figure 2D,E,F, the SphK2-downregulated cell tumors were much smaller than the control cell tumors. Together, these results showed that SphK2 is critical for EOC cell growth in vitro and in vivo.

\section{SphK2 controls cell cycle progression of EOC cells}

To investigate the cellular mechanisms by which SphK2 was required for ovarian cancer cell growth, we used SKOV3 to 
A
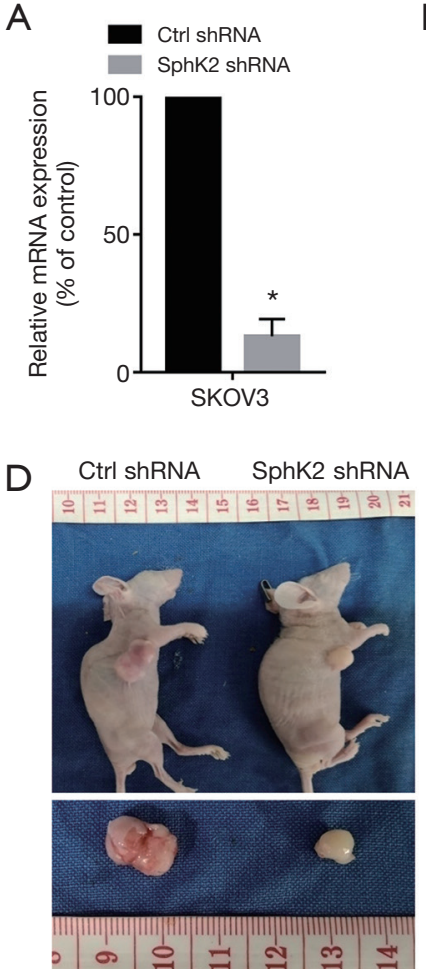

B

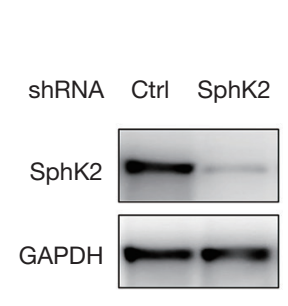

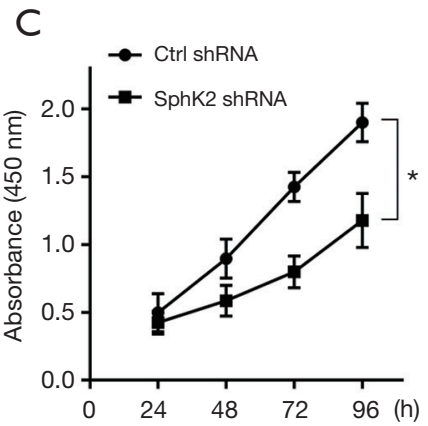

$\mathrm{F}$
$\mathrm{E}$

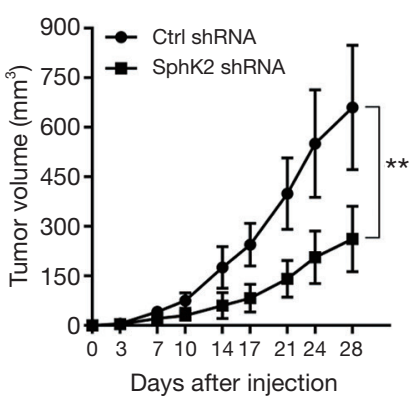

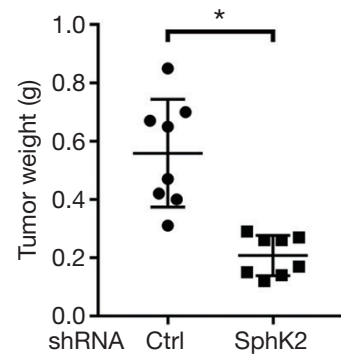

Figure 2 SphK2 inhibition suppresses the growth of EOC cells in vitro and in vivo. (A) SKOV3 cells transfected with control shRNA or SphK2 shRNA. Expression of SphK2 mRNA levels determined by PCR and normalized to GAPDH mRNA. (B) Protein levels of SphK2 as determined by Western blot. (C) A significant reduction in cell growth rate in the SphK2 shRNA group is observed by the cellular proliferation assay in ovarian cancer cells. (D) Representative images of tumors in subcutaneous ovarian cancer xenograft model. Mean tumor volume (E) and weight (F) in the SphK2 shRNA group are significantly reduced compared with the control group (8 mice in each group). The experiments were repeated 3 times. ${ }^{*}, \mathrm{P}<0.05$; ${ }^{* *}, \mathrm{P}<0.01$. SphK2, sphingosine kinase 2; EOC, epithelial ovarian cancer; shRNA, short hairpin RNA; GAPDH, glyceraldehyde-3-phosphate dehydrogenase.

analyze the effects of SphK2 down-regulation on cell cycle and apoptosis. Compared to the control cells, shRNA-mediated SphK2 inhibition resulted in an accumulation of SKOV3 in the G0/G1 phase to reduce cells in the $\mathrm{S}$ phase (Figure $3 A$ ). Moreover, subsequent Western blot analysis indicated that SphK2 down-regulation reduced the levels of cyclin D1 and phosphor $\mathrm{Rb}$ (Figure 3B). In contrast to the strong effects on cell cycle progression, SphK2 down-regulation did not affect the apoptotic rate of ovarian cancer cells (Figure 3C). Together, these data suggested that SphK2 inhibition in ovarian cancer cells induces cell cycle G0/G1 arrest.

\section{SphK2 inbibition in ovarian cancer cells induces an expression profile linked to the MAPK signaling pathway and MYC targets}

To investigate the underlying molecular mechanisms whereby SphK2 is required for EOC cell growth, we performed a microarray analysis of ovarian cancer SKOV3 cells transfected with shRNA targeting SphK2. Heatmap clustering of the top 100 upregulated or downregulated genes (Figure 4A, Table S1) showed a high degree of reproducibility between triplicates (26) and a significant differentiation between the SphK2 knockdown cells and the cells transfected with scramble control. Gene set enrichment analysis (GSEA) was used to analyze the SphK2-regulated gene signatures. The Kyoto Encyclopedia of Genes and Genomes (KEGG) pathway analysis revealed that genes deregulated upon SphK2 suppression were enriched for gene sets such as mitogen-activated protein kinase (MAPK) signaling pathway (Figure 4B,C). Consistent with the link to the MAPK pathway, GSEA analysis revealed significant associations with the gene set involving ERK/MAPK targets (Figure $4 D$ ). Intriguingly, the results of GSEA showed the 
A

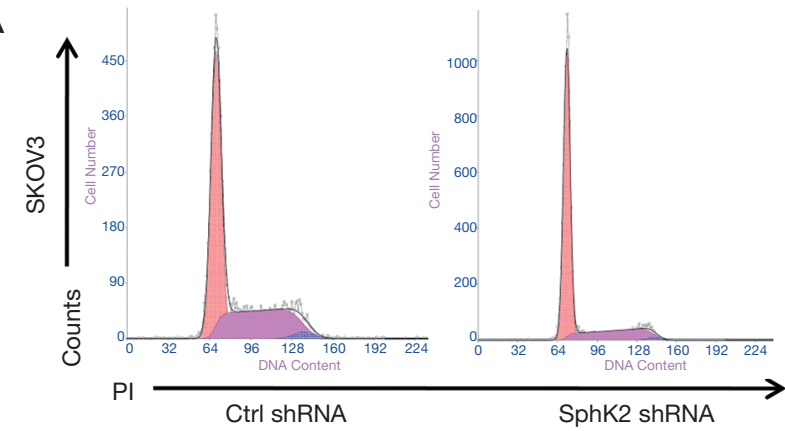

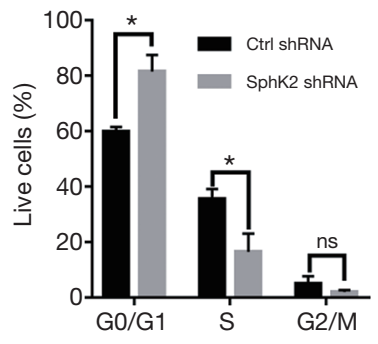

B

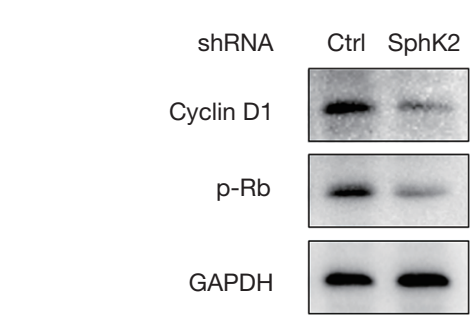

Cyclin D1

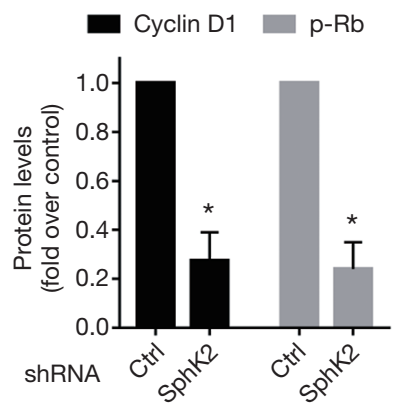

C
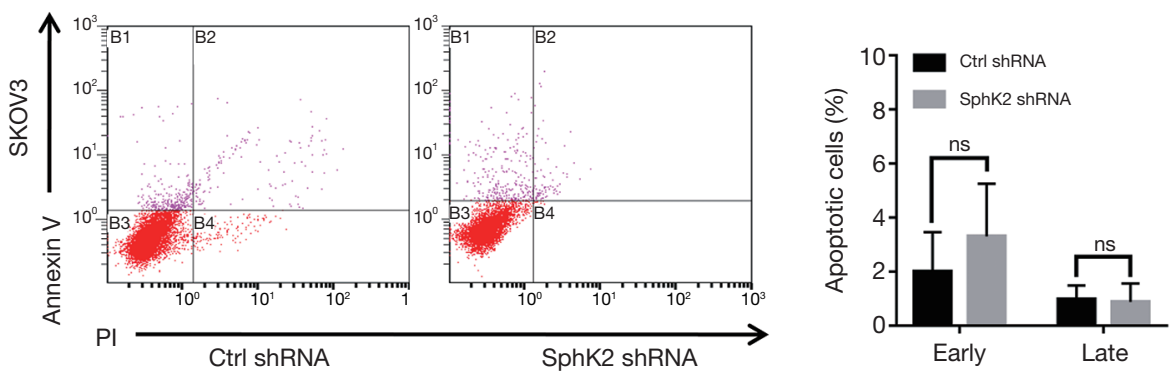

Figure 3 SphK2 inhibition in EOC cells causes an arrest in the G0/G1 phase of the cell cycle. (A) Representative flow cytometry charts of SKOV3 cells transfected with SphK2 shRNA or Ctrl shRNA and stained by PI. The percentage of cells in each cell cycle population was quantified. (B) Western blot analysis of cyclin D1 and p-Rb in ovarian cancer cells transfected with SphK2 shRNA or Ctrl shRNA. Right panels show that densitometric analysis of cyclin D1 and p- Rb (normalized to GAPDH) is reduced in SKOV3. (C) Bar graphs showing the percentage of apoptotic cells of SKOV3 transfected with SphK2 shRNA or Ctrl shRNA. The experiments were repeated 3 times. *, $\mathrm{P}<0.05$. SphK2, sphingosine kinase 2; EOC, epithelial ovarian cancer; Ctrl, control; shRNA, short hairpin RNA; PI, propidium iodide; $\mathrm{p}-\mathrm{Rb}$, phosphate retinoblastoma; GAPDH, glyceraldehyde-3-phosphate dehydrogenase.

expression changes in response to SphK2 inhibition were most significantly correlated with the gene signature of two individual subgroups of MYC targets data sets (Figure 4E,F, Tables S2,S3).

\section{SphK2 down-regulation may induce c-Myc inhibition partly through the ERK1/2 pathway}

The ERK1/2 pathway is one of the best-characterized members of the MAPK family. Moreover, it has been demonstrated to play essential roles in cell cycle progression and cell survival (27). Thus, we detected the expression level of phosphorylated ERK1/2 protein by Western blot and confirmed that SphK2 inhibition down-regulated the ERK1/2 pathway activation (Figure $5 A$ ). The most widely studied gene in the MYC family, c-Myc, is involved in cell cycle regulation, cell proliferation, and differentiation $(28,29)$. Down-regulation of c-Myc after SphK2 blockage was also confirmed by Western blot (Figure $5 A$ ). It has been reported that c-Myc is an inducible gene of ERK (30). To determine whether the down-regulation 
A

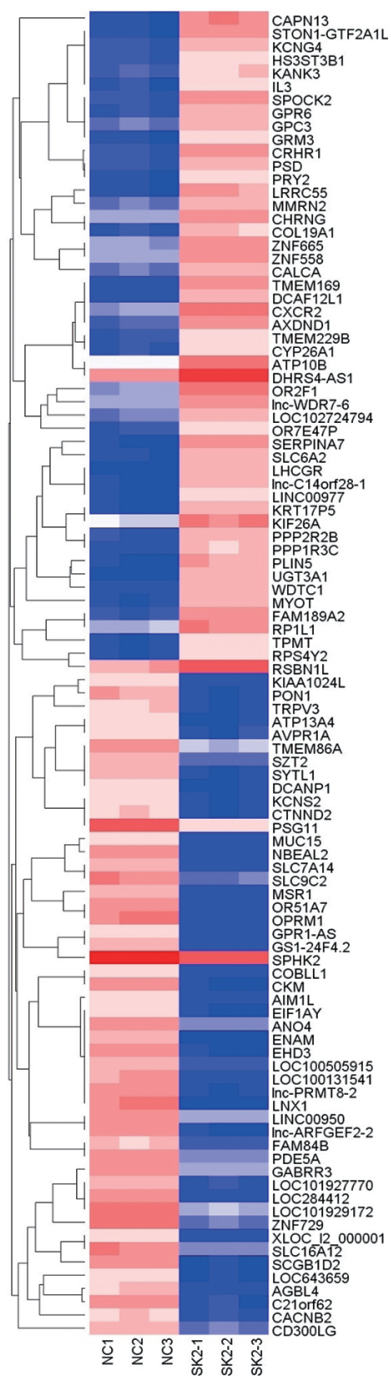

B

\begin{tabular}{lcc}
\hline KEGG pathway & NES score & FDR \\
\hline MAPK signaling pathway & -2.22 & 0.000 \\
\hline Renal cell carcinoma & -1.81 & 0.061 \\
\hline GNRH signaling pathway & -1.80 & 0.041 \\
\hline Melanoma & -1.72 & 0.064 \\
\hline VEGF signaling pathway & -1.68 & 0.051 \\
\hline Regulation of autophagy & 1.92 & 0.000 \\
\hline One carbon pool by folate & 1.75 & 0.000 \\
\hline ABC transporters & 1.62 & 0.092 \\
\hline Parkinsons disease & 1.51 & 0.192 \\
\hline Rig I like receptor signaling pathway & 1.48 & 0.208 \\
\hline
\end{tabular}

C
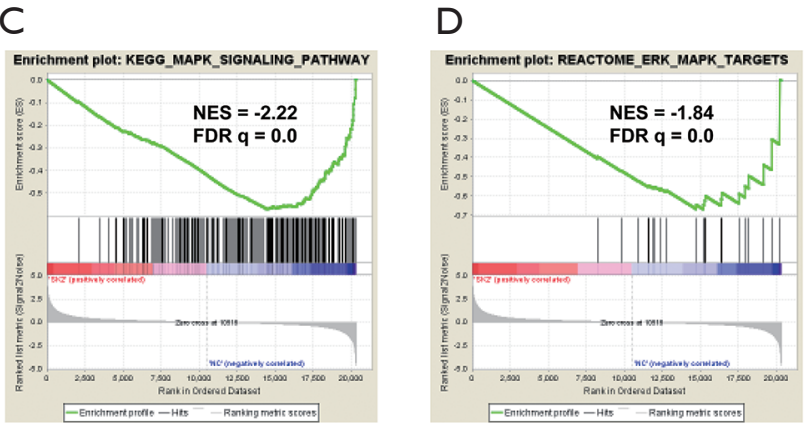

$\mathrm{E}$

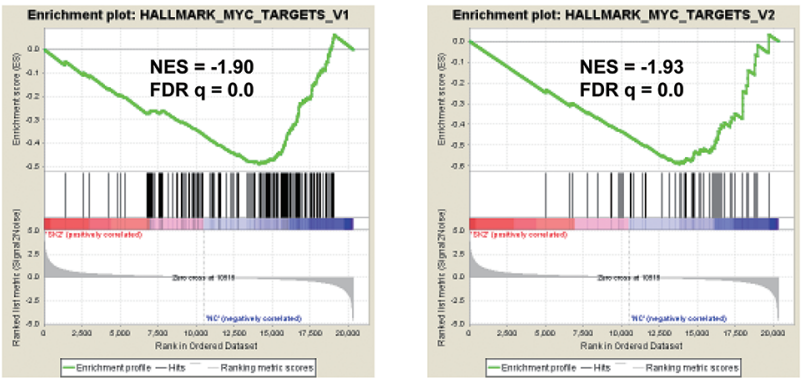

Figure 4 SphK2 suppression induces an expression profile correlating to MAPK signaling pathway and MYC targets. (A) Heatmap of 100 genes with most significant changes in gene expression of SKOV3 cells transfected with SphK2 shRNA or Ctrl shRNA. Blue and red colors represent low and high relative gene expression levels, respectively. (B) List of the ten most significant KEGG gene set pathways correlating to gene expression changes resulting from SphK2 knockdown in SKOV3 cells. (C,D,E,F) GSEA shows significant association between SphK2 level and several gene sets, including MAPK signaling pathway (C), ERK MAPK targets (D), MYC target V1 (E) and MYC target V2 (F). SphK2, sphingosine kinase 2; MAPK, mitogen-activated protein kinase; MYC, myelocytomatosis; shRNA, short hairpin RNA; KEGG, Kyoto Encyclopedia of Genes and Genomes; ERK, extracellular regulated protein kinases; GSEA, gene set enrichment analysis.

of c-Myc was partly through the ERK1/2 pathway in EOC cells, we investigated the effect of ERK1/2 blockage on c-Myc expression. As expected, ERK1/2 blockage by U0126, a specific inhibitor of the ERK1/2 pathway, significantly inhibited c-Myc expression (Figure 5B). Moreover, ERK1/2 knockdown also resulted in the suppression of c-Myc (Figure 5C). These results suggested that SphK2 down-regulation caused
c-Myc and ERK1/2 pathway inhibition. Knockdown of SPHK2 induced by ERK1/2 pathway suppression may contribute to the down-regulation of c-Myc.

\section{Discussion}

In the current study, we found that SphK2 played a crucial 
A
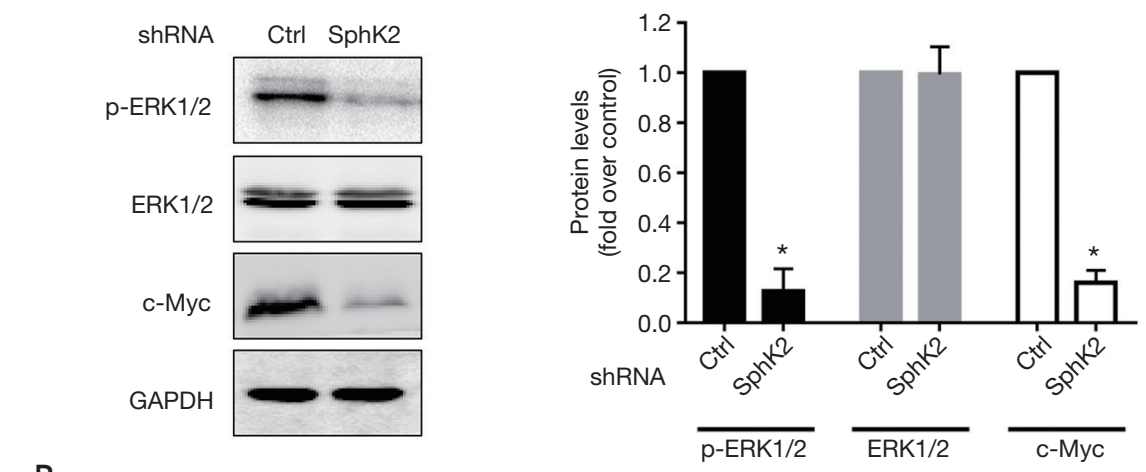

B
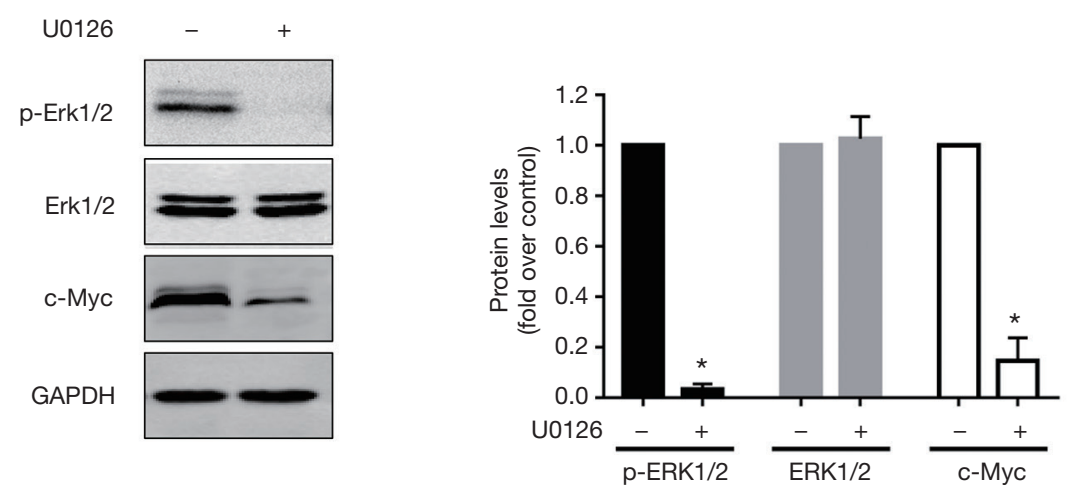

C
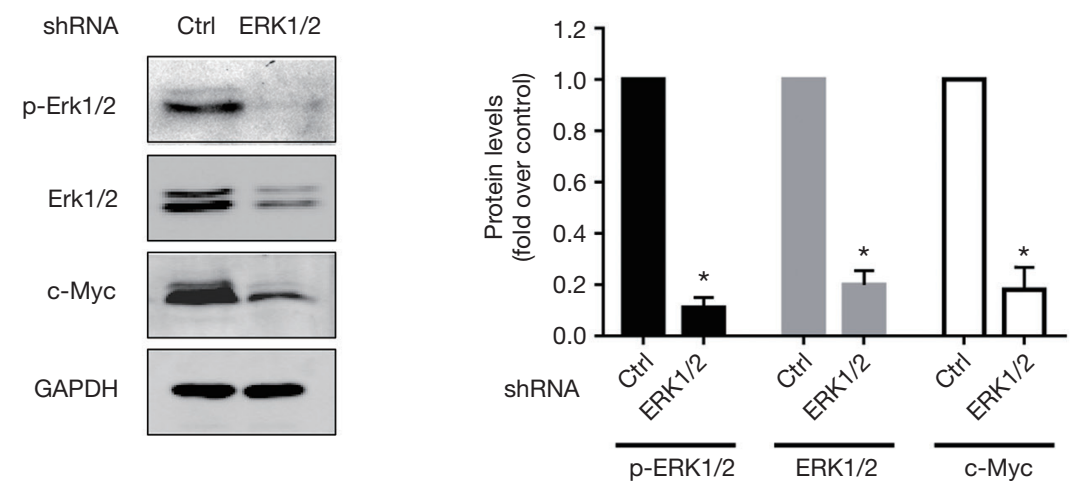

Figure 5 SphK2 blockage induces c-Myc inhibition partly through ERK1/2 pathway. (A) Western blot analysis of p-ERK1/2, ERK1/2, and c-Myc in ovarian cancer cells transfected with SphK2 shRNA or Ctrl shRNA. SphK2 inhibition reduces expressions of p-ERK1/2 and c-Myc not affecting ERK1/2. (B) Pretreatment with U0126, inhibitor of ERK1/2 pathway, also reduces the expressions of p-ERK and c-Myc in ovarian cancer cells. (C) Western blot analysis of p-ERK1/2, ERK1/2, and c-Myc in ovarian cancer cells transfected with ERK1/2 siRNA or Ctrl siRNA. Right panels show densitometric analysis of p-ERK1/2, ERK1/2, and c-Myc (normalized to GAPDH) corresponding to the bands shown in the Western blots. The experiments were repeated 3 times. *, $\mathrm{P}<0.05$. SphK2, sphingosine kinase 2; c-Myc, cellular myelocytomatosis; ERK, extracellular regulated protein kinases; shRNA, short hairpin RNA; Ctrl, control; siRNA, small interference RNA; GAPDH, glyceraldehyde-3-phosphate dehydrogenase. 
role in EOC progression and that knockdown of SphK2 could significantly inhibit the proliferation of cancer. Especially, our study provided the following new findings: (I) SphK2, up-regulated in ovarian cancer tissues, correlated with a poor prognosis in this deadly disease; (II) SphK2 blockage in EOC cells caused significant inhibition of cell growth and an arrest in the G1/G0 phase; (III) inhibition of SphK2 down-regulated ERK/c-Myc pathway, which might partly-mediate $\mathrm{SphK} 2$ induced cell cycle arrest.

The SphKs exhibit 2 isoforms, SphK1 and SphK2. A key player in cancer progression, SphK1 (31), is elevated markedly in ovarian cancer $(13,32)$. Our previous studies showed SphK1 was required for EOC metastasis and angiogenesis $(12,13)$, and its activation inversely correlated with survival in EOC patients (20). Moreover, it is reported that $\mathrm{S} 1 \mathrm{P}$, generated by SphK, was elevated in ascites of ovarian cancer patients (33) and was also reported to regulate the migration, invasion, and angiogenesis of ovarian cancer cells. However, the expression and function of SphK2 are far from elucidated $(33,34)$. Here, we showed that the level of SphK2 was elevated in EOC specimens. Notably, the SphK2 level was closely correlated with the well-known prognostic parameters of EOC, including FIGO stage, histological grade, lymph node metastasis, and ascites.

Moreover, the elevated expression level of SphK2 was found to be associated with poor prognosis and was a prognostic factor for predicting OS and RFS. These findings implied that SphK2 might be a potentially important factor in EOC progression. Beach et al. reported that SphK2 mRNA was not overexpressed in serous ovarian cancer than normal ovarian tissue (35). However, their study did not distinguish the expression level of SphK2 between ovarian epithelial tissue and adjacent stroma. Therefore, further studies are needed to detect the SphK2 expression quantities of normal ovary epithelial tissue and EOC tissue. Moreover, SphK1 was reported to be highly expressed in tumor stroma and was required for the differentiation and tumor-promoting function of cancer-associated fibroblasts (35). However, the roles of SphK2 in cells of the tumor stroma remain unclear and require exploration in the future.

The contribution of SphK2 to cancer progression is unclear. Some studies have found that high-level expression of SphK2 could induce cell cycle arrest and apoptosis $(14,15)$. Despite the notion that SphK2 is a pro-apoptotic factor, several studies have emerged indicating SphK2 promoted cancer survival. Knockdown or inhibition of SphK2 has been shown to induce apoptosis in some cancer types $(16,17)$. Moreover, in some cancer cell lines, targeting SphK2 has an even more powerful anti-cancer effect than targeting SphK1 (36,37). In this study, the relationship between SphK2 levels and EOC patients' prognosis suggests a role for SphK2 in promoting EOC. Therefore, we investigated the effect of SphK2 downregulation on the growth of EOC cells in vitro. As expected, SphK2 blockage by shRNA significantly inhibited ovarian cancer proliferation. Following the in vitro results, SphK2 down-regulation also reduced tumor growth in a mouse ovarian cancer model. These results indicated that SphK2 was associated with EOC progression and presented the possibility that SphK2 might serve as a new target for EOC therapy. In future studies, more EOC cell lines and primary EOC cells should be tested further to verify the role of SphK2 in EOC progression.

Inhibition of SphK2 has been reported to be associated with both caspase-dependent and autophagy-dependent cell death $(17,38)$. In ovarian cancer, SphK2 down-regulated cells displayed only modest levels of early and late apoptotic cells. Consistent with the lack of apoptosis, genes involved in apoptosis were not changed significantly in SphK2 downregulated cells (data not shown). In contrast to the modest effects in cell apoptosis, SphK2 depleted cells showed a dramatic accumulation in the G0/G1 phase compared to the controls. Moreover, SphK2 down-regulation caused cyclin D1 and phosphor-Rb inhibition, several key cell cycle checkpoint factors.

Furthermore, autophagy is implicated in both cell death and cell survival. The potential regulation of autophagy by SphK2 and its roles in EOC growth need to be investigated in a future study. Taken together, our data indicated that the primary cellular mechanism, whereby inhibition of SphK2 prevented cell growth of ovarian cancer cells, is mediated through the inhibition of cell cycle progression rather than induction of apoptosis.

Another new finding in this study was the downregulation of the ERK/c-Myc pathway due to SphK2 inhibition. Our results are consistent with previous studies demonstrating that SphK2 inhibition down-regulated c-Myc expression (21,39). Extensive studies have demonstrated the essential roles of ERK1/2 signaling in ovarian cancer survival (40-42). Moreover, c-Myc, an inducible ERK gene, was reported to be a key mediator of the progression of ovarian cancer $(43,44)$. Furthermore, ERK or c-Myc inhibition has been reported to cause a G0/G1 block in the cell cycle of ovarian cancer cells $(40,43)$. Therefore, it is possible that inhibition of SphK2 resulted in the repression 
of the ERK/c-Myc pathway and subsequently caused G0/ G1 cell cycle arrest, which consequently reduced cell proliferation in human EOC.

Moreover, it was reported that ERK1 could activate SphK2 by direct phosphorylation in breast cancer (45), which indicated that ERK1 was the upstream activator of SphK2. This report, together with our observation that SphK2 blockage resulted in significant ERK activation inhibition, suggests ERK1 might be placed in both upstream and downstream of SphK2 signaling and might have a dual role in the initiation and amplification of the SphK2 signaling loop in EOC cells. This speculation needs to be further investigated in the future. Besides, the biological effects of SphK2 activation chiefly rely on its product S1P. Therefore, further studies are needed to explore the functions of extracellular and intracellular S1P generated by SphK2. Furthermore, the connection between SphK2 and $\mathrm{ERK} / \mathrm{c}-\mathrm{Myc}$ pathway needs to be further validated in tumor tissue sections.

\section{Acknowledgments}

Funding: This study was supported by the grants from the National Natural Science Foundation of China (NSFC) (81974401 to Lan Dai, and 81772770 to Wen $\mathrm{Di}$ ), the Science and Technology Commission of Shanghai municipality (18ZR1423100 to Lan Dai), and the Shanghai Municipal Commission of Health and Family Planning (2017YQ035 to Lan Dai).

\section{Footnote}

Reporting Checklist: The authors have completed the ARRIVE reporting checklist. Available at http://dx.doi. org/10.21037/atm-20-6742

Data Sharing Statement: Available at http://dx.doi. org/10.21037/atm-20-6742

Conflicts of Interest: All authors have completed the ICMJE uniform disclosure form (available at http://dx.doi. org/10.21037/atm-20-6742). The authors have no conflicts of interest to declare.

Ethical Statement: The authors are accountable for all aspects of the work in ensuring that questions related to the accuracy or integrity of any part of the work are appropriately investigated and resolved. All animal experiments were performed according to the Laboratory Animal Guidelines provided by Shanghai Jiao Tong University School of Medicine. The experimental protocols were approved by the Institutional Animal Care and Use Committee of Shanghai Jiao Tong University School of Medicine (A2018021). All procedures performed in this study involving human participants were in accordance with the Declaration of Helsinki (as revised in 2013). The study was approved by the Institutional Ethical Committee of Renji Hospital (RA-2019-076) and informed consent was provided by all participants.

Open Access Statement: This is an Open Access article distributed in accordance with the Creative Commons Attribution-NonCommercial-NoDerivs 4.0 International License (CC BY-NC-ND 4.0), which permits the noncommercial replication and distribution of the article with the strict proviso that no changes or edits are made and the original work is properly cited (including links to both the formal publication through the relevant DOI and the license). See: https://creativecommons.org/licenses/by-nc-nd/4.0/.

\section{References}

1. Siegel RL, Miller KD, Jemal A. Cancer statistics, 2019. CA Cancer J Clin 2019;69:7-34.

2. Bowtell DD, Bohm S, Ahmed AA, et al. Rethinking ovarian cancer II: reducing mortality from high-grade serous ovarian cancer. Nat Rev Cancer 2015;15:668-79.

3. Agarwal R, Kaye SB. Ovarian cancer: strategies for overcoming resistance to chemotherapy. Nat Rev Cancer 2003;3:502-16.

4. Schwartz M, Camacho-Vanegas O, Wood AM, et al. Applying Precision Medicine to Ovarian Cancer: Proofof-Principle for a "Molecular Second Look". Int J Gynecol Cancer 2018;28:479-85.

5. Yap TA, Carden CP, Kaye SB. Beyond chemotherapy: targeted therapies in ovarian cancer. Nat Rev Cancer 2009;9:167-81.

6. Ogretmen B. Sphingolipid metabolism in cancer signalling and therapy. Nat Rev Cancer 2018;18:33-50.

7. Takabe K, Paugh SW, Milstien S, et al. "Inside-out" signaling of sphingosine-1-phosphate: therapeutic targets. Pharmacol Rev 2008;60:181-95.

8. Dai L, Xia P, Di W. Sphingosine 1-phosphate: a potential molecular target for ovarian cancer therapy? Cancer Invest 2014;32:71-80.

9. Acharya S, Yao J, Li P, et al. Sphingosine Kinase 1 
Signaling Promotes Metastasis of Triple-Negative Breast Cancer. Cancer Res 2019;79:4211-26.

10. Lee CF, Dang A, Hernandez E, et al. Activation of sphingosine kinase by lipopolysaccharide promotes prostate cancer cell invasion and metastasis via SphK1/ S1PR4/matriptase. Oncogene 2019;38:5580-98.

11. Hart PC, Chiyoda T, Liu X, et al. SPHK1 Is a Novel Target of Metformin in Ovarian Cancer. Mol Cancer Res 2019;17:870-81.

12. Dai L, Liu Y, Xie L, et al. Sphingosine kinase 1/ sphingosine-1-phosphate $(\mathrm{S} 1 \mathrm{P}) / \mathrm{S} 1 \mathrm{P}$ receptor axis is involved in ovarian cancer angiogenesis. Oncotarget 2017;8:74947-61.

13. Zhang H, Wang Q, Zhao Q, et al. MiR-124 inhibits the migration and invasion of ovarian cancer cells by targeting SphK1. J Ovarian Res 2013;6:84.

14. Maceyka M, Sankala H, Hait NC, et al. SphK1 and SphK2, sphingosine kinase isoenzymes with opposing functions in sphingolipid metabolism. J Biol Chem 2005;280:37118-29.

15. Liu H, Toman RE, Goparaju SK, et al. Sphingosine kinase type 2 is a putative $\mathrm{BH} 3$-only protein that induces apoptosis. J Biol Chem 2003;278:40330-6.

16. Liang J, Zhang X, He S, et al. Sphk2 RNAi nanoparticles suppress tumor growth via downregulating cancer cell derived exosomal microRNA. J Control Release 2018;286:348-57.

17. Dai L, Smith CD, Foroozesh M, et al. The sphingosine kinase 2 inhibitor ABC294640 displays anti-non-small cell lung cancer activities in vitro and in vivo. Int J Cancer 2018;142:2153-62.

18. Neubauer HA, Pham DH, Zebol JR, et al. An oncogenic role for sphingosine kinase 2. Oncotarget 2016;7:6488699.

19. Chen Y, Deng X, Chen W, et al. Silencing of microRNA-708 promotes cell growth and epithelialto-mesenchymal transition by activating the SPHK2/ AKT/beta-catenin pathway in glioma. Cell Death Dis 2019; 10:448

20. Song K, Dai L, Long X, et al. Follicle-stimulating hormone promotes the proliferation of epithelial ovarian cancer cells by activating sphingosine kinase. Sci Rep 2020;10:13834.

21. Wallington-Beddoe CT, Powell JA, Tong D, et al. Sphingosine kinase 2 promotes acute lymphoblastic leukemia by enhancing MYC expression. Cancer Res 2014;74:2803-15.

22. Song K, Dai L, Long X, et al. Sphingosine kinase 2 inhibitor ABC294640 displays anti-epithelial ovarian cancer activities in vitro and in vivo. Onco Targets Ther 2019;12:4437-49.

23. Dai L, Qi Y, Chen J, et al. Sphingosine kinase (SphK) 1 and SphK2 play equivalent roles in mediating insulin's mitogenic action. Mol Endocrinol 2014;28:197-207.

24. Dai L, Gu L, Ding C, et al. TWEAK promotes ovarian cancer cell metastasis via NF-kappaB pathway activation and VEGF expression. Cancer Lett 2009;283:159-67.

25. Wang Y, Wang Y, Xiang J, et al. Knockdown of CRM1 inhibits the nuclear export of p27(Kip1) phosphorylated at serine 10 and plays a role in the pathogenesis of epithelial ovarian cancer. Cancer Lett 2014;343:6-13.

26. Deng W, Wang Y, Liu Z, et al. HemI: a toolkit for illustrating heatmaps. PLoS One 2014;9:e111988.

27. Chang F, Steelman LS, Shelton JG, et al. Regulation of cell cycle progression and apoptosis by the Ras/Raf/MEK/ ERK pathway (Review). Int J Oncol 2003;22:469-80.

28. Junttila MR, Westermarck J. Mechanisms of MYC stabilization in human malignancies. Cell Cycle 2008;7:592-6.

29. Pelengaris $\mathrm{S}$, Khan $M$. The c-MYC oncoprotein as a treatment target in cancer and other disorders of cell growth. Expert Opin Ther Targets 2003;7:623-42.

30. Sears R, Nuckolls F, Haura E, et al. Multiple Rasdependent phosphorylation pathways regulate Myc protein stability. Genes Dev 2000;14:2501-14.

31. Zheng X, Li W, Ren L, et al. The sphingosine kinase-1/ sphingosine-1-phosphate axis in cancer: Potential target for anticancer therapy. Pharmacol Ther 2019;195:85-99.

32. Yang YL, Ji C, Cheng L, et al. Sphingosine kinase-1 inhibition sensitizes curcumin-induced growth inhibition and apoptosis in ovarian cancer cells. Cancer Sci 2012;103:1538-45.

33. Wang D, Zhao Z, Caperell-Grant A, et al. S1P differentially regulates migration of human ovarian cancer and human ovarian surface epithelial cells. Mol Cancer Ther 2008;7:1993-2002.

34. Park KS, Kim MK, Lee HY, et al. S1P stimulates chemotactic migration and invasion in OVCAR3 ovarian cancer cells. Biochem Biophys Res Commun 2007;356:239-44.

35. Beach JA, Aspuria PJ, Cheon DJ, et al. Sphingosine kinase 1 is required for TGF-beta mediated fibroblasttomyofibroblast differentiation in ovarian cancer. J Neuropathol Exp Neurol 2005;64:695-705.

36. Van Brocklyn JR, Jackson CA, Pearl DK, et al. Sphingosine kinase-1 expression correlates with poor 


\section{Page 14 of 14}

survival of patients with glioblastoma multiforme: roles of sphingosine kinase isoforms in growth of glioblastoma cell lines. J Neuropathol Exp Neurol 2005;

64:695-705.

37. Gao P, Smith CD. Ablation of sphingosine kinase-2 inhibits tumor cell proliferation and migration. Mol Cancer Res 2011;9:1509-19.

38. Dai L, Bai A, Smith CD, et al. ABC294640, A Novel Sphingosine Kinase 2 Inhibitor, Induces Oncogenic VirusInfected Cell Autophagic Death and Represses Tumor Growth. Mol Cancer Ther 2017;16:2724-34.

39. Venkata JK, An N, Stuart R, et al. Inhibition of sphingosine kinase 2 downregulates the expression of c-Myc and Mcl-1 and induces apoptosis in multiple myeloma. Blood 2014;124:1915-25.

40. Jiang XL, Gao JC, Jiang L, et al. Expression and significance of MAPK/ERK in the specimens and cells of

Cite this article as: Dai L, Wang W, Liu Y, Song K, Di W. Inhibition of sphingosine kinase 2 down-regulates ERK/c-Myc pathway and reduces cell proliferation in human epithelial ovarian cancer. Ann Transl Med 2021;9(8):645. doi: 10.21037/ atm-20-6742

\section{Dai et al. Inhibition of SphK2 reduces EOC proliferation}

epithelial ovarian cancer. Zhonghua Fu Chan Ke Za Zhi 2019;54:541-7.

41. Liu SB, Lin XP, Xu Y, et al. DAXX promotes ovarian cancer ascites cell proliferation and migration by activating the ERK signaling pathway. J Ovarian Res 2018;11:90.

42. Liu S, Zha J, Lei M. Inhibiting ERK/Mnk/eIF4E broadly sensitizes ovarian cancer response to chemotherapy. Clin Transl Oncol 2018;20:374-81.

43. Reyes-Gonzalez JM, Armaiz-Pena GN, Mangala LS, et al. Targeting c-MYC in Platinum-Resistant Ovarian Cancer. Mol Cancer Ther 2015;14:2260-9.

44. Zeng M, Kwiatkowski NP, Zhang T, et al. Targeting MYC dependency in ovarian cancer through inhibition of CDK7 and CDK12/13. Elife 2018;7:e39030.

45. Hait NC, Bellamy A, Milstien S, et al. Sphingosine kinase type 2 activation by ERK-mediated phosphorylation. J Biol Chem 2007;282:12058-65. 
A

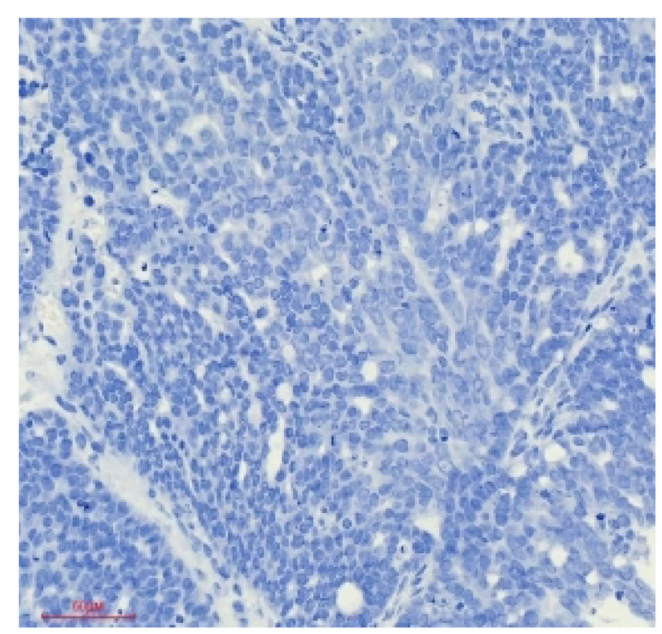

B

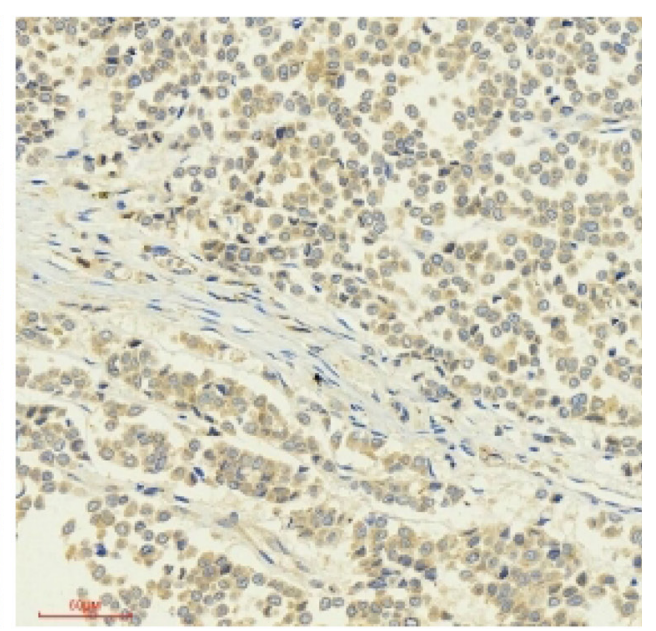

Figure S1 The negative and positive control of IHC. (A) Negative control: IHC staining of serous ovarian cancer tissue. Normal rabbit immunoglobulins were used as primary antibodies. (B) Positive control: IHC staining of SphK2 in human breast cancer tissue. The scale bar represents $60 \mu \mathrm{m}$. IHC, immunohistochemistry. 
Table S1 100 most significant changed genes of SKOV3 cells transfected with SphK2 shRNA

\begin{tabular}{|c|c|c|c|c|c|c|c|c|}
\hline GeneSymbol & $\begin{array}{c}\text { Normalized signal } \\
(\log 2) \text { of } N C 1\end{array}$ & $\begin{array}{c}\text { Normalized signal } \\
(\log 2) \text { of NC2 }\end{array}$ & $\begin{array}{c}\text { Normalized signal } \\
\text { (log2) of NC3 }\end{array}$ & $\begin{array}{l}\text { Normalized signal } \\
(\log 2) \text { of SphK2-1 }\end{array}$ & $\begin{array}{l}\text { Normalized signal } \\
(\log 2) \text { of SphK2-2 }\end{array}$ & $\begin{array}{l}\text { Normalized signal } \\
\text { (log2) of SphK2-3 }\end{array}$ & Gene_ID & Accession \\
\hline CAPN13 & 1.723441 & 1.821052 & 1.618743 & 6.354988 & 6.531311 & 6.218926 & 92291 & AK074418 \\
\hline STON1-GTF2A1L & 1.663951 & 1.801454 & 1.463038 & 6.213173 & 6.139173 & 6.350677 & 286749 & NM_172311 \\
\hline TMEM169 & 1.699259 & 1.836763 & 1.769648 & 6.167417 & 6.093417 & 6.304921 & 92691 & NM_138390 \\
\hline SERPINA7 & 1.658265 & 1.506262 & 1.457353 & 6.122579 & 6.23361 & 6.002284 & 6906 & NM_000354 \\
\hline FAM189A2 & 1.962786 & 1.826724 & 2.060397 & 6.226503 & 6.137235 & 6.152502 & 9413 & NM_004816 \\
\hline OR2F1 & 2.702354 & 2.903988 & 2.865853 & 6.808706 & 6.933034 & 6.906317 & 26211 & NM_012369 \\
\hline CRHR1 & 1.984403 & 2.121907 & 1.879706 & 6.081669 & 5.992402 & 6.1927 & 1394 & NM_004382 \\
\hline CXCR2 & 2.808716 & 2.946219 & 2.906327 & 6.876749 & 6.787482 & 6.98778 & 3579 & NM_001557 \\
\hline PLIN5 & 1.710634 & 1.605937 & 1.59034 & 5.689104 & 5.584406 & 5.63021 & 440503 & NM_001013706 \\
\hline LHCGR & 1.621096 & 1.436671 & 1.452973 & 5.595267 & 5.506 & 5.536373 & 3973 & NM_000233 \\
\hline LRRC55 & 1.689812 & 1.853311 & 1.600545 & 5.655633 & 5.779961 & 5.596739 & 219527 & NM_001005210 \\
\hline SPOCK2 & 1.925069 & 2.062572 & 1.724156 & 5.848576 & 5.959607 & 5.98608 & 9806 & NM_014767 \\
\hline UGT3A1 & 1.622032 & 1.548031 & 1.517334 & 5.456356 & 5.526745 & 5.593859 & 133688 & NM_152404 \\
\hline$A X D N D 1$ & 2.172279 & 2.26989 & 2.242669 & 5.927011 & 5.806717 & 6.064515 & 126859 & NM_144696 \\
\hline$D C A F 12 L 1$ & 1.735571 & 1.873074 & 1.833181 & 5.389985 & 5.300718 & 5.501017 & 139170 & NM_178470 \\
\hline WDTC1 & 1.791825 & 1.717825 & 1.687128 & 5.423995 & 5.494385 & 5.349995 & 23038 & NM_015023 \\
\hline$P S D$ & 1.91226 & 2.009871 & 1.791966 & 5.438491 & 5.333794 & 5.575995 & 5662 & NM_002779 \\
\hline KRT17P5 & 1.669043 & 1.484619 & 1.500921 & 5.160319 & 5.071052 & 5.25793 & 339240 & NR_001443 \\
\hline Inc-C14orf28-1 & 1.686466 & 1.502042 & 1.518344 & 5.157382 & 5.068115 & 5.098488 & \multicolumn{2}{|c|}{ Inc-C14orf28-1:3 } \\
\hline MYOT & 1.798899 & 1.597987 & 1.709632 & 5.208702 & 5.33303 & 5.306313 & 9499 & NM_006790 \\
\hline CHRNG & 3.026047 & 3.16355 & 2.921349 & 6.407561 & 6.318293 & 6.271499 & 1146 & NM_005199 \\
\hline$R P 1 L 1$ & 3.26524 & 3.113236 & 3.349304 & 6.599514 & 6.494816 & 6.479219 & 94137 & NM_178857 \\
\hline ZNF665 & 2.859678 & 2.930067 & 2.75498 & 6.158239 & 6.228628 & 6.084238 & 79788 & NM_024733 \\
\hline GPR6 & 1.879664 & 2.003992 & 1.711542 & 5.134558 & 5.191142 & 5.232169 & 2830 & NM_005284 \\
\hline$P P P 2 R 2 B$ & 1.959794 & 1.855097 & 1.8395 & 5.212759 & 5.108062 & 5.350263 & 5521 & NM_001271948 \\
\hline COL19A1 & 1.859919 & 1.997422 & 1.755221 & 5.084918 & 4.99565 & 4.948856 & 1310 & NM_001858 \\
\hline$P P P 1 R 3 C$ & 1.831188 & 1.72649 & 1.710894 & 5.012698 & 4.908001 & 5.150202 & 5507 & NM_005398 \\
\hline SLC6A2 & 1.822543 & 1.67054 & 1.62163 & 4.999193 & 5.110224 & 5.136697 & 6530 & NM_001043 \\
\hline KCNG4 & 1.9361 & 2.060428 & 1.767977 & 5.055805 & 4.966538 & 5.153416 & 93107 & NM_172347 \\
\hline ZNF558 & 2.949439 & 3.019828 & 2.844741 & 6.05615 & 6.126539 & 5.982149 & 148156 & AK055494 \\
\hline RPS4Y2 & 1.724131 & 1.572128 & 1.808195 & 4.777621 & 4.888652 & 4.657327 & 140032 & NM_001039567 \\
\hline PRY2 & 1.673558 & 1.771169 & 1.553264 & 4.721532 & 4.616835 & 4.859036 & 442862 & NM_001002758 \\
\hline TPMT & 1.6696 & 1.5956 & 1.73999 & 4.668473 & 4.594472 & 4.805976 & 7172 & NM_000367 \\
\hline ATP10B & 3.802994 & 3.900605 & 3.873383 & 6.787623 & 6.667328 & 6.925126 & 23120 & NM_025153 \\
\hline
\end{tabular}

Table S1 (continued) 
Table S1 (continued)

\begin{tabular}{|c|c|c|c|c|c|c|c|c|}
\hline GeneSymbol & $\begin{array}{l}\text { Normalized signal } \\
(\log 2) \text { of } N C 1\end{array}$ & $\begin{array}{c}\text { Normalized signal } \\
(\log 2) \text { of NC2 }\end{array}$ & $\begin{array}{c}\text { Normalized signal } \\
\text { (log2) of NC3 }\end{array}$ & $\begin{array}{l}\text { Normalized signal } \\
(\log 2) \text { of SphK2-1 }\end{array}$ & $\begin{array}{l}\text { Normalized signal } \\
\text { (log2) of SphK2-2 }\end{array}$ & $\begin{array}{l}\text { Normalized signal } \\
\text { (log2) of SphK2-3 }\end{array}$ & Gene_ID & Accession \\
\hline LINC00977 & 1.753568 & 1.569143 & 1.585445 & 4.737893 & 4.648626 & 4.678999 & 728724 & NR_033916 \\
\hline CALCA & 2.448535 & 2.546146 & 2.343838 & 5.431335 & 5.607658 & 5.295273 & 796 & NM_001033952 \\
\hline GRM3 & 1.720528 & 1.844856 & 1.552405 & 4.693338 & 4.749921 & 4.790949 & 2913 & NM_000840 \\
\hline DHRS4-AS1 & 6.203654 & 6.341158 & 6.301265 & 9.17191 & 9.082642 & 9.282941 & 55449 & NR_023921 \\
\hline MMRN2 & 2.360667 & 2.524166 & 2.2714 & 5.310428 & 5.434756 & 5.408039 & 79812 & NM_024756 \\
\hline TMEM229B & 1.886745 & 2.024249 & 1.957134 & 4.805802 & 4.731801 & 4.943305 & 161145 & XR_245666 \\
\hline Inc-WDR7-6 & 2.97997 & 3.143469 & 3.13053 & 5.881037 & 5.79177 & 5.822144 & \multicolumn{2}{|c|}{ Inc-WDR7-6:1 } \\
\hline HS3ST3B1 & 1.925637 & 2.049965 & 1.757514 & 4.753639 & 4.664371 & 4.85125 & 9953 & NM_006041 \\
\hline KANK3 & 2.119384 & 2.243712 & 1.951261 & 4.915372 & 4.826104 & 5.012982 & 256949 & NM_198471 \\
\hline IL3 & 1.795209 & 1.919537 & 1.627086 & 4.570705 & 4.481438 & 4.668316 & 3562 & NM_000588 \\
\hline LOC102724794 & 2.389774 & 2.553272 & 2.540333 & 5.144572 & 5.2689 & 5.085679 & 102724794 & BC009926 \\
\hline CYP26A1 & 1.758812 & 1.896316 & 1.856423 & 4.471999 & 4.382732 & 4.583031 & 1592 & NM_057157 \\
\hline GPC3 & 2.455046 & 2.579374 & 2.286923 & 5.167371 & 5.223955 & 5.264982 & 2719 & NM_004484 \\
\hline KIF26A & 3.871365 & 3.68694 & 3.703242 & 6.515574 & 6.426307 & 6.613185 & 26153 & NM_015656 \\
\hline RSBN1L & 5.618802 & 5.466799 & 5.702866 & 8.253452 & 8.364483 & 8.133158 & 222194 & BM468849 \\
\hline OR7E47P & 1.740766 & 1.9424 & 1.904265 & 4.371512 & 4.49584 & 4.469123 & 26628 & NR_120438 \\
\hline KIAA1024L & 4.577214 & 4.39279 & 4.409092 & 1.7674 & 1.678133 & 1.865011 & 100127206 & NM_001257308 \\
\hline GABRR3 & 5.933716 & 6.058045 & 6.031327 & 3.114626 & 3.171209 & 3.040625 & 200959 & NM_001105580 \\
\hline ATP13A4 & 4.451427 & 4.549038 & 4.521816 & 1.629519 & 1.509225 & 1.767023 & 84239 & NM_032279 \\
\hline CD300LG & 5.173277 & 5.021274 & 5.06858 & 2.342911 & 2.519234 & 2.20685 & 146894 & NM_145273 \\
\hline MUC15 & 4.515982 & 4.315069 & 4.426715 & 1.667706 & 1.792034 & 1.765317 & 143662 & NM_145650 \\
\hline COBLL1 & 4.641321 & 4.778824 & 4.536623 & 1.789184 & 1.699916 & 1.653122 & 22837 & NM_014900 \\
\hline GPR1-AS & 4.620425 & 4.744753 & 4.452302 & 1.738813 & 1.795397 & 1.836424 & 101669764 & NR_104359 \\
\hline AIM1L & 4.768345 & 4.865956 & 4.838735 & 1.869546 & 1.749252 & 1.764849 & 55057 & NM_001039775 \\
\hline EIF1AY & 4.597503 & 4.735006 & 4.695113 & 1.692469 & 1.603202 & 1.618469 & 9086 & NM_004681 \\
\hline LINC00950 & 5.974328 & 5.789904 & 5.806205 & 3.066059 & 2.976792 & 3.007166 & 92973 & NR_024006 \\
\hline KCNS2 & 4.556707 & 4.681035 & 4.388585 & 1.643771 & 1.554503 & 1.741382 & 3788 & NM_020697 \\
\hline FAM84B & 5.05626 & 4.920198 & 5.15387 & 2.12875 & 2.039483 & 2.05475 & 157638 & NM_174911 \\
\hline TMEM86A & 6.237049 & 6.374553 & 6.307438 & 3.308936 & 3.234936 & 3.44644 & 144110 & NM_153347 \\
\hline DCANP1 & 4.575955 & 4.713459 & 4.673566 & 1.642116 & 1.552848 & 1.753147 & 140947 & NM_130848 \\
\hline AVPR1A & 4.703392 & 4.801003 & 4.773781 & 1.757399 & 1.637105 & 1.894903 & 140947 & NM_130848 \\
\hline LOC643659 & 4.565467 & 4.728966 & 4.4762 & 1.599728 & 1.724056 & 1.540834 & 643659 & AK056971 \\
\hline SPHK2 & 11.1287 & 11.2662 & 10.92778 & 8.114125 & 8.225156 & 8.251628 & 56848 & NM_020126 \\
\hline XLOC_12_000001 & 4.821869 & 4.747869 & 4.717172 & 1.806649 & 1.877038 & 1.732648 & TCONS & 12_00001923 \\
\hline
\end{tabular}

Table S1 (continued) 
Table S1 (continued)

\begin{tabular}{|c|c|c|c|c|c|c|c|c|}
\hline GeneSymbol & $\begin{array}{c}\text { Normalized signal } \\
(\log 2) \text { of NC1 }\end{array}$ & $\begin{array}{c}\text { Normalized signal } \\
(\log 2) \text { of NC2 }\end{array}$ & $\begin{array}{l}\text { Normalized signal } \\
\quad(\log 2) \text { of NC3 }\end{array}$ & $\begin{array}{l}\text { Normalized signal } \\
(\log 2) \text { of SphK2-1 }\end{array}$ & $\begin{array}{l}\text { Normalized signal } \\
(\log 2) \text { of SphK2-2 }\end{array}$ & $\begin{array}{l}\text { Normalized signal } \\
(\log 2) \text { of SphK2-3 }\end{array}$ & Gene_ID & Accession \\
\hline CACNB2 & 4.92142 & 5.01903 & 4.816722 & 1.801885 & 1.978208 & 1.665823 & 783 & AK128769 \\
\hline$A G B L 4$ & 4.918867 & 5.016478 & 4.989257 & 1.758832 & 1.869863 & 1.654134 & 84871 & AK027348 \\
\hline SZT2 & 5.466478 & 5.603982 & 5.536867 & 2.260969 & 2.186968 & 2.398472 & 23334 & NM_015284 \\
\hline PDE5A & 5.870075 & 5.765377 & 6.033573 & 2.64736 & 2.542663 & 2.588466 & 8654 & NM_001083 \\
\hline ANO4 & 5.864137 & 5.961748 & 5.934527 & 2.63483 & 2.514535 & 2.530132 & 121601 & NM_178826 \\
\hline TRPV3 & 4.885111 & 4.81111 & 4.9555 & 1.649519 & 1.575518 & 1.787022 & 162514 & NM_145068 \\
\hline CTNND2 & 4.930207 & 5.06771 & 4.825509 & 1.650221 & 1.560953 & 1.761252 & 1501 & NM_001332 \\
\hline LOC100505915 & 5.401384 & 5.564882 & 5.551943 & 2.083278 & 1.994011 & 2.024384 & 100505915 & NR_125434 \\
\hline LOC101927770 & 5.182151 & 5.34565 & 5.332711 & 1.862326 & 1.986654 & 1.803432 & 101927770 & NR_110051 \\
\hline PSG11 & 8.099883 & 8.197494 & 7.979589 & 4.453627 & 4.348929 & 4.59113 & 5680 & NM_002785 \\
\hline MSR1 & 5.382703 & 5.546202 & 5.293436 & 1.729903 & 1.854232 & 1.827514 & 4481 & NM_138715 \\
\hline LOC101929172 & 6.799461 & 6.96296 & 6.950021 & 3.145706 & 3.270034 & 3.086812 & 101929172 & NR_104677 \\
\hline GS1-24F4.2 & 5.341271 & 5.465599 & 5.173148 & 1.648424 & 1.705008 & 1.746035 & 100652791 & NR_045217 \\
\hline SYTL1 & 5.372369 & 5.509873 & 5.442759 & 1.668484 & 1.594483 & 1.805987 & 84958 & NM_032872 \\
\hline LOC100131541 & 5.566218 & 5.729717 & 5.716778 & 1.808116 & 1.718849 & 1.749222 & 100131541 & AY358248 \\
\hline SLC7A14 & 5.420327 & 5.268324 & 5.219414 & 1.649379 & 1.76041 & 1.786882 & 57709 & NM_020949 \\
\hline SLC16A12 & 6.502291 & 6.350288 & 6.301378 & 2.689233 & 2.800265 & 2.568939 & 387700 & NM_213606 \\
\hline ENAM & 5.457047 & 5.594551 & 5.554658 & 1.617998 & 1.52873 & 1.543997 & 10117 & NM_031889 \\
\hline EHD3 & 5.696453 & 5.833956 & 5.794064 & 1.709446 & 1.620179 & 1.635446 & 30845 & NM_014600 \\
\hline PON1 & 5.733017 & 5.628319 & 5.612722 & 1.70984 & 1.605143 & 1.847344 & 5444 & NM_000446 \\
\hline LOC284412 & 5.739756 & 5.903255 & 5.890316 & 1.705748 & 1.830076 & 1.646855 & 284412 & NR_029390 \\
\hline Inc-ARFGEF2-2 & 5.854138 & 5.669713 & 5.686015 & 1.678698 & 1.589431 & 1.619804 & - & AK126019 \\
\hline C21orf62 & 5.925917 & 6.023528 & 5.996307 & 1.745434 & 1.921757 & 1.609373 & 56245 & NM_019596 \\
\hline SLC9C2 & 6.592031 & 6.440028 & 6.391118 & 2.364139 & 2.47517 & 2.501642 & 284525 & NM_178527 \\
\hline Inc-PRMT8-2 & 5.965704 & 6.129202 & 6.116263 & 1.730351 & 1.641084 & 1.671458 & - & BX096603 \\
\hline CKM & 5.93621 & 6.073713 & 5.831512 & 1.698426 & 1.609159 & 1.562365 & 1158 & NM_001824 \\
\hline ZNF729 & 6.886741 & 6.95713 & 6.782043 & 2.459713 & 2.530103 & 2.385713 & 100287226 & NM_001242680 \\
\hline OR51A7 & 6.135948 & 6.337582 & 6.299447 & 1.651183 & 1.775511 & 1.748794 & 119687 & NM_001004749 \\
\hline NBEAL2 & 6.147131 & 5.946218 & 6.057864 & 1.643982 & 1.76831 & 1.741593 & 23218 & NM_015175 \\
\hline OPRM1 & 6.384385 & 6.586019 & 6.547884 & 1.753117 & 1.877445 & 1.850728 & 4988 & NM_000914 \\
\hline SCGB1D2 & 6.390669 & 6.238666 & 6.474733 & 1.601543 & 1.712574 & 1.481249 & 10647 & NM_006551 \\
\hline$L N X 1$ & 6.436681 & 6.600179 & 6.58724 & 1.602565 & 1.513298 & 1.543671 & 84708 & NM_032622 \\
\hline
\end{tabular}

SphK2, sphingosine kinase 2; shRNA, short hairpin RNA; NC, negative control; ID, identification. 
Table S2 HALLMARK_MYC_TARGETS_V1 (GSEA details)

\begin{tabular}{|c|c|c|c|c|}
\hline Name & Probe & Rank metric score & Running ES & Core enrichment \\
\hline row_0 & UBA2 & 0.75295496 & -0.051006 & No \\
\hline row_1 & SMARCC1 & 0.441985309 & -0.100376 & No \\
\hline row_2 & SNRPD1 & 0.38816756 & -0.111042 & No \\
\hline row_3 & HNRNPU & 0.275371343 & -0.1672 & No \\
\hline row_4 & MRPS18B & 0.232058719 & -0.192292 & No \\
\hline row_5 & MYC & 0.22204265 & -0.195249 & No \\
\hline row_6 & RRM1 & 0.207781792 & -0.203505 & No \\
\hline row_7 & TUFM & 0.141880929 & -0.272709 & No \\
\hline row_8 & HNRNPA1 & 0.139995366 & -0.271861 & No \\
\hline row_9 & CCT2 & 0.138858914 & -0.269999 & No \\
\hline row_10 & UBE2L3 & 0.135779649 & -0.270392 & No \\
\hline row_11 & XRCC6 & 0.134474739 & -0.268882 & No \\
\hline row_12 & TOMM70A & 0.134389117 & -0.265936 & No \\
\hline row_13 & NHP2 & 0.132905856 & -0.264562 & No \\
\hline row_14 & RANBP1 & 0.132039443 & -0.262614 & No \\
\hline row_15 & AP3S1 & 0.130847111 & -0.260744 & No \\
\hline row_16 & TRIM28 & 0.127579734 & -0.261233 & No \\
\hline row_17 & GSPT1 & 0.125280172 & -0.261529 & No \\
\hline row_18 & PSMA6 & 0.123724453 & -0.260324 & No \\
\hline row_19 & PSMD8 & 0.119761556 & -0.261892 & No \\
\hline row_20 & POLE3 & 0.109567322 & -0.270549 & No \\
\hline row_21 & IMPDH2 & 0.1076736 & -0.271015 & No \\
\hline row_22 & NCBP2 & 0.107079968 & -0.269313 & No \\
\hline row_23 & PSMA2 & 0.106365785 & -0.267528 & No \\
\hline row_24 & CAD & 0.104962997 & -0.26677 & No \\
\hline row_25 & CCNA2 & 0.103091829 & -0.266601 & No \\
\hline row_26 & XPO1 & 0.102699079 & -0.264408 & No \\
\hline row_27 & HNRNPD & 0.101317599 & -0.263239 & No \\
\hline row_28 & RPL22 & 0.100557022 & -0.261345 & No \\
\hline row_29 & H2AFZ & 0.09926755 & -0.260622 & No \\
\hline row_30 & YWHAQ & 0.085262917 & -0.276851 & No \\
\hline row_31 & PRPF31 & 0.075119957 & -0.289997 & No \\
\hline row_32 & GNB2L1 & 0.06710469 & -0.299911 & No \\
\hline row_33 & SNRPA1 & 0.063945368 & -0.302707 & No \\
\hline row_34 & HNRNPC & 0.056119565 & -0.312088 & No \\
\hline
\end{tabular}

Table S2 (continued) 
Table S2 (continued)

\begin{tabular}{|c|c|c|c|c|}
\hline Name & Probe & Rank metric score & Running ES & Core enrichment \\
\hline row_35 & RPS5 & 0.055559836 & -0.311363 & No \\
\hline row_36 & PSMD7 & 0.05439749 & -0.311359 & No \\
\hline row_37 & RPL34 & 0.052501261 & -0.312691 & No \\
\hline row_38 & XPOT & 0.052221946 & -0.311896 & No \\
\hline row_39 & CLNS1A & 0.052013975 & -0.310858 & No \\
\hline row_40 & PCNA & 0.045902282 & -0.317307 & No \\
\hline row_41 & NDUFAB1 & 0.045787055 & -0.316318 & No \\
\hline row_42 & NOLC1 & 0.045039382 & -0.31619 & No \\
\hline row_43 & IFRD1 & 0.044070806 & -0.316432 & No \\
\hline row_44 & IARS & 0.036820859 & -0.324833 & No \\
\hline row_45 & SNRPB2 & 0.03491557 & -0.326434 & No \\
\hline row_46 & NME1 & 0.028353699 & -0.33459 & No \\
\hline row_47 & PSMB2 & 0.026027661 & -0.337444 & No \\
\hline row_48 & HSPD1 & 0.025041765 & -0.338585 & No \\
\hline row_49 & HNRNPA3 & 0.025041739 & -0.33799 & No \\
\hline row_50 & GNL3 & 0.024733359 & -0.337799 & No \\
\hline row_51 & MRPL23 & 0.020495223 & -0.341876 & No \\
\hline row_52 & MCM7 & 0.020237211 & -0.341841 & No \\
\hline row_53 & RAN & 0.019865079 & -0.342163 & No \\
\hline row_54 & HSPE1 & 0.017159631 & -0.345128 & No \\
\hline row_55 & CDK4 & 0.015760908 & -0.346886 & No \\
\hline row_56 & PSMA1 & 0.015633628 & -0.346763 & No \\
\hline row_57 & PPM1G & 0.014878112 & -0.347203 & No \\
\hline row_58 & RPLP0 & 0.013469636 & -0.348619 & No \\
\hline row_59 & CSTF2 & 0.009877304 & -0.353246 & No \\
\hline row_60 & PSMD14 & 0.00620796 & -0.357513 & No \\
\hline row_61 & RPL14 & 0.004616383 & -0.359437 & No \\
\hline row_62 & PPIA & 0.002007276 & -0.362763 & No \\
\hline row_63 & SRSF2 & -0.014217941 & -0.385741 & No \\
\hline row_64 & PGK1 & -0.018825812 & -0.391197 & No \\
\hline row_65 & RPL18 & -0.019023182 & -0.390893 & No \\
\hline row_66 & RPS3 & -0.021245448 & -0.392819 & No \\
\hline row_67 & RSL1D1 & -0.021759583 & -0.393244 & No \\
\hline row_68 & RPS10 & -0.026557757 & -0.399012 & No \\
\hline row_69 & PSMC4 & -0.03433685 & -0.408912 & No \\
\hline
\end{tabular}

Table S2 (continued) 
Table S2 (continued)

\begin{tabular}{|c|c|c|c|c|}
\hline Name & Probe & Rank metric score & Running ES & Core enrichment \\
\hline row_70 & HDGF & -0.035441697 & -0.409905 & No \\
\hline row_71 & PSMA7 & -0.035912897 & -0.409597 & No \\
\hline row_72 & FBL & -0.035930786 & -0.408792 & No \\
\hline row_73 & HPRT1 & -0.037053823 & -0.4093 & No \\
\hline row_74 & TRA2B & -0.039255165 & -0.410996 & No \\
\hline row_75 & RRP9 & -0.040565018 & -0.411917 & No \\
\hline row_76 & UBE2E1 & -0.040684555 & -0.411198 & No \\
\hline row_77 & LSM2 & -0.054305311 & -0.428956 & No \\
\hline row_78 & CDK2 & -0.054875091 & -0.428247 & No \\
\hline row_79 & TXNL4A & -0.065190256 & -0.44029 & No \\
\hline row_80 & GLO1 & -0.065689772 & -0.439225 & No \\
\hline row_81 & TFDP1 & -0.067489475 & -0.439505 & No \\
\hline row_82 & VBP1 & -0.072169319 & -0.443147 & No \\
\hline row_83 & C1QBP & -0.078820862 & -0.450054 & No \\
\hline row_84 & PTGES3 & -0.083282806 & -0.453829 & No \\
\hline row_85 & LSM7 & -0.084112555 & -0.452673 & No \\
\hline row_86 & SSBP1 & -0.084295653 & -0.450768 & No \\
\hline row_87 & EPRS & -0.085567839 & -0.450421 & No \\
\hline row_88 & TCP1 & -0.11050456 & -0.476567 & No \\
\hline row_89 & SNRPG & -0.115020134 & -0.478992 & No \\
\hline row_90 & COPS5 & -0.11821723 & -0.480051 & No \\
\hline row_91 & APEX1 & -0.11884474 & -0.477722 & No \\
\hline row_92 & RPL6 & -0.122988902 & -0.479511 & No \\
\hline row_93 & YWHAE & -0.124661528 & -0.477787 & No \\
\hline row_94 & DDX18 & -0.130250916 & -0.48119 & No \\
\hline row_95 & GOT2 & -0.131161422 & -0.478965 & No \\
\hline row_96 & HDDC2 & -0.132284909 & -0.476663 & No \\
\hline row_97 & SRPK1 & -0.146622136 & -0.487118 & Yes \\
\hline row_98 & NOP56 & -0.148529723 & -0.485174 & Yes \\
\hline row_99 & EIF4G2 & -0.149976537 & -0.483048 & Yes \\
\hline row_100 & RUVBL2 & -0.151623368 & -0.481428 & Yes \\
\hline row_101 & FAM120A & -0.157058418 & -0.483201 & Yes \\
\hline row_102 & $\mathrm{DHX} 15$ & -0.160647944 & -0.482954 & Yes \\
\hline row_103 & ODC1 & -0.161853611 & -0.480693 & Yes \\
\hline row_104 & PSMC6 & -0.163321689 & -0.478398 & Yes \\
\hline
\end{tabular}

Table S2 (continued) 
Table S2 (continued)

\begin{tabular}{|c|c|c|c|c|}
\hline Name & Probe & Rank metric score & Running ES & Core enrichment \\
\hline row_105 & VDAC3 & -0.169090107 & -0.479786 & Yes \\
\hline row_106 & SSB & -0.171148852 & -0.477751 & Yes \\
\hline row_107 & EIF2S1 & -0.17292048 & -0.475575 & Yes \\
\hline row_108 & PSMD3 & -0.174922407 & -0.473947 & Yes \\
\hline row_109 & MCM6 & -0.177651942 & -0.472552 & Yes \\
\hline row_110 & CBX3 & -0.178819522 & -0.469194 & Yes \\
\hline row_111 & PWP1 & -0.183310106 & -0.468705 & Yes \\
\hline row_112 & ORC2 & -0.192079425 & -0.471382 & Yes \\
\hline row_113 & HNRNPA2B1 & -0.193108097 & -0.467635 & Yes \\
\hline row_114 & SRSF3 & -0.19625476 & -0.465797 & Yes \\
\hline row_115 & KPNA2 & -0.19806917 & -0.462924 & Yes \\
\hline row_116 & EIF2S2 & -0.200332135 & -0.459501 & Yes \\
\hline row_117 & ILF2 & -0.204584301 & -0.458408 & Yes \\
\hline row_118 & SNRPD3 & -0.204796284 & -0.453738 & Yes \\
\hline row_119 & СCT5 & -0.20759435 & -0.450986 & Yes \\
\hline row_120 & RNPS1 & -0.209443837 & -0.447198 & Yes \\
\hline row_121 & MAD2L1 & -0.214259252 & -0.445924 & Yes \\
\hline row_122 & TYMS & -0.215162262 & -0.441454 & Yes \\
\hline row_123 & POLD2 & -0.225046277 & -0.442851 & Yes \\
\hline row_124 & RPS6 & -0.225984603 & -0.438471 & Yes \\
\hline row_125 & BUB3 & -0.228153363 & -0.434982 & Yes \\
\hline row_126 & STARD7 & -0.229092807 & -0.430677 & Yes \\
\hline row_127 & EEF1B2 & -0.231023133 & -0.426773 & Yes \\
\hline row_128 & DEK & -0.231684506 & -0.421662 & Yes \\
\hline row_129 & HSP90AB1 & -0.232376978 & -0.416733 & Yes \\
\hline row_130 & PHB2 & -0.236070171 & -0.413403 & Yes \\
\hline row_131 & PSMD1 & -0.23623085 & -0.408036 & Yes \\
\hline row_132 & SYNCRIP & -0.239132211 & -0.404583 & Yes \\
\hline row_133 & PHB & -0.23959583 & -0.399036 & Yes \\
\hline row_134 & PSMA4 & -0.241566703 & -0.394931 & Yes \\
\hline row_135 & PRDX3 & -0.243438482 & -0.39093 & Yes \\
\hline row_136 & NAP1L1 & -0.243779406 & -0.385383 & Yes \\
\hline row_137 & TARDBP & -0.245692894 & -0.380832 & Yes \\
\hline row_138 & SERBP1 & -0.248633698 & -0.376856 & Yes \\
\hline row_139 & U2AF1 & -0.25003773 & -0.371855 & Yes \\
\hline
\end{tabular}

Table S2 (continued) 
Table S2 (continued)

\begin{tabular}{|c|c|c|c|c|}
\hline Name & Probe & Rank metric score & Running ES & Core enrichment \\
\hline row_140 & PCBP1 & -0.250153869 & -0.365908 & Yes \\
\hline row_141 & PRPS2 & -0.251016259 & -0.360437 & Yes \\
\hline row_142 & CUL1 & -0.25416702 & -0.355734 & Yes \\
\hline row_143 & NPM1 & -0.26072982 & -0.353356 & Yes \\
\hline row_144 & VDAC1 & -0.262458354 & -0.347762 & Yes \\
\hline row_145 & RFC4 & -0.266047537 & -0.344067 & Yes \\
\hline row_146 & G3BP1 & -0.269299239 & -0.340244 & Yes \\
\hline row_147 & CDC20 & -0.273317069 & -0.336178 & Yes \\
\hline row_148 & NOP16 & -0.278643012 & -0.333225 & Yes \\
\hline row_149 & EXOSC7 & -0.280433416 & -0.327501 & Yes \\
\hline row_150 & EIF3B & -0.281347871 & -0.321458 & Yes \\
\hline row_151 & MCM5 & -0.288626343 & -0.319061 & Yes \\
\hline row_152 & SET & -0.296802521 & -0.316272 & Yes \\
\hline row_153 & CNBP & -0.29850772 & -0.310218 & Yes \\
\hline row_154 & ABCE1 & -0.300362378 & -0.303921 & Yes \\
\hline row_155 & CYC1 & -0.306511402 & -0.299859 & Yes \\
\hline row_156 & USP1 & -0.306835771 & -0.292614 & Yes \\
\hline row_157 & $\mathrm{ERH}$ & -0.307143658 & -0.285511 & Yes \\
\hline row_158 & CDC45 & -0.309706509 & -0.27934 & Yes \\
\hline row_159 & NCBP1 & -0.311334372 & -0.272931 & Yes \\
\hline row_160 & PABPC4 & -0.31315735 & -0.26628 & Yes \\
\hline row_161 & KPNB1 & -0.313886315 & -0.258818 & Yes \\
\hline row_162 & MRPL9 & -0.314340293 & -0.251693 & Yes \\
\hline row_163 & SRSF7 & -0.314915717 & -0.244753 & Yes \\
\hline row_164 & SNRPD2 & -0.317407101 & -0.238497 & Yes \\
\hline row_165 & ССТ7 & -0.31781745 & -0.231091 & Yes \\
\hline row_166 & EIF3J & -0.328673124 & -0.228635 & Yes \\
\hline row_167 & KARS & -0.336773813 & -0.225144 & Yes \\
\hline row_168 & RPS2 & -0.339905143 & -0.218006 & Yes \\
\hline row_169 & AIMP2 & -0.356947273 & -0.217111 & Yes \\
\hline row_170 & LDHA & -0.361901045 & -0.210938 & Yes \\
\hline row_171 & CANX & -0.374194205 & -0.207053 & Yes \\
\hline row_172 & EIF1AX & -0.399766922 & -0.206033 & Yes \\
\hline row_173 & EIF3D & -0.403767079 & -0.197923 & Yes \\
\hline row_174 & SLC25A3 & -0.413684905 & -0.190916 & Yes \\
\hline
\end{tabular}

Table S2 (continued) 
Table S2 (continued)

\begin{tabular}{|c|c|c|c|c|}
\hline Name & Probe & Rank metric score & Running ES & Core enrichment \\
\hline row_175 & RAD23B & -0.417804658 & -0.182225 & Yes \\
\hline row_176 & PSMB3 & -0.417925298 & -0.17229 & Yes \\
\hline row_177 & ACP1 & -0.424158156 & -0.164141 & Yes \\
\hline row_178 & PABPC1 & -0.424715102 & -0.154442 & Yes \\
\hline row_179 & HDAC2 & -0.438016325 & -0.147799 & Yes \\
\hline row_180 & CCT4 & -0.450546712 & -0.140413 & Yes \\
\hline row_181 & SF3B3 & -0.470833033 & -0.134727 & Yes \\
\hline row_182 & DDX21 & -0.476490498 & -0.12459 & Yes \\
\hline row_183 & SRM & -0.481136769 & -0.114343 & Yes \\
\hline row_184 & COX5A & -0.495382637 & -0.106932 & Yes \\
\hline row_185 & ССТ3 & -0.516387105 & -0.09937 & Yes \\
\hline row_186 & ETF1 & -0.526386082 & -0.089039 & Yes \\
\hline row_187 & PA2G4 & -0.558176398 & -0.081872 & Yes \\
\hline row_188 & EIF4E & -0.61265403 & -0.076733 & Yes \\
\hline row_189 & EIF4A1 & -0.617235363 & -0.062805 & Yes \\
\hline row_190 & MCM2 & -0.631449163 & -0.050572 & Yes \\
\hline row_191 & EIF4H & -0.653316855 & -0.038762 & Yes \\
\hline row_192 & DUT & -0.661347389 & -0.023883 & Yes \\
\hline row_193 & PRDX4 & -0.684686899 & -0.011774 & Yes \\
\hline row_194 & SNRPA & -0.703109384 & 0.0027078 & Yes \\
\hline row_195 & SRSF1 & -0.735901058 & 0.0154889 & Yes \\
\hline row_196 & MCM4 & -0.753878117 & 0.0311778 & Yes \\
\hline row_197 & HNRNPR & -0.772973239 & 0.0470725 & Yes \\
\hline row_198 & SF3A1 & -0.793221414 & 0.0635974 & Yes \\
\hline
\end{tabular}

GSEA, Gene set enrichment analysis; ES, enrichment score. 
Table S3 HALLMARK_MYC_TARGETS_V2 (GSEA details)

\begin{tabular}{|c|c|c|c|c|}
\hline Name & Probe & Rank metric score & Running ES & Core enrichment \\
\hline row_0 & MYC & 0.22204265 & -0.23330317 & No \\
\hline row_1 & SORD & 0.147695452 & -0.3013698 & No \\
\hline row_2 & MPHOSPH10 & 0.142654836 & -0.29727072 & No \\
\hline row_3 & MYBBP1A & 0.100131452 & -0.34115317 & No \\
\hline row_4 & RABEPK & 0.076708563 & -0.36774597 & No \\
\hline row_5 & NOLC1 & 0.045039382 & -0.40718013 & No \\
\hline row_6 & WDR74 & 0.042263422 & -0.40828314 & No \\
\hline row_7 & HSPD1 & 0.025041765 & -0.42954922 & No \\
\hline row_8 & GNL3 & 0.024733359 & -0.42827404 & No \\
\hline row_9 & IPO4 & 0.020873915 & -0.43101102 & No \\
\hline row_10 & HSPE1 & 0.017159631 & -0.4348436 & No \\
\hline row_11 & CDK4 & 0.015760908 & -0.4358668 & No \\
\hline row_12 & TMEM97 & -0.003955827 & -0.46135676 & No \\
\hline row_13 & PLK1 & -0.005095467 & -0.4626284 & No \\
\hline row_14 & PPRC1 & -0.011475308 & -0.47104335 & No \\
\hline row_15 & FARSA & -0.031356916 & -0.49556538 & No \\
\hline row_16 & SLC19A1 & -0.038516253 & -0.50259405 & No \\
\hline row_17 & RRP9 & -0.040565018 & -0.50258344 & No \\
\hline row_18 & NDUFAF4 & -0.080790021 & -0.54914 & No \\
\hline row_19 & TBRG4 & -0.100404747 & -0.56580997 & No \\
\hline row_20 & PPAN & -0.119243138 & -0.5789049 & No \\
\hline row_21 & DDX18 & -0.130250916 & -0.5817764 & Yes \\
\hline row_22 & IMP4 & -0.136173263 & -0.5777336 & Yes \\
\hline row_23 & UTP20 & -0.145401374 & -0.57649803 & Yes \\
\hline row_24 & NOP56 & -0.148529723 & -0.5690842 & Yes \\
\hline row_25 & $\mathrm{RCL} 1$ & -0.151270196 & -0.56148 & Yes \\
\hline row_26 & GRWD1 & -0.166755065 & -0.56610096 & Yes \\
\hline row_27 & RRP12 & -0.173035681 & -0.5603343 & Yes \\
\hline row_28 & NIP7 & -0.173853666 & -0.5494367 & Yes \\
\hline row_29 & MAP3K6 & -0.17443873 & -0.53790724 & Yes \\
\hline row_30 & CBX3 & -0.178819522 & -0.52971894 & Yes \\
\hline row_31 & HK2 & -0.197324991 & -0.53187096 & Yes \\
\hline row_32 & NOP2 & -0.198687613 & -0.51914924 & Yes \\
\hline row_33 & NOC4L & -0.214178205 & -0.51658326 & Yes \\
\hline row_34 & PHB & -0.23959583 & -0.51934516 & Yes \\
\hline
\end{tabular}

Table S3 (continued) 
Table S3 (continued)

\begin{tabular}{|c|c|c|c|c|}
\hline Name & Probe & Rank metric score & Running ES & Core enrichment \\
\hline row_35 & BYSL & -0.248257443 & -0.50884444 & Yes \\
\hline row_36 & NPM1 & -0.26072982 & -0.49777272 & Yes \\
\hline row_37 & EXOSC5 & -0.26488322 & -0.4816831 & Yes \\
\hline row_38 & DCTPP1 & -0.271444321 & -0.46755153 & Yes \\
\hline row_39 & NOP16 & -0.278643012 & -0.45311677 & Yes \\
\hline row_40 & PRMT3 & -0.280235976 & -0.4344825 & Yes \\
\hline row_41 & MCM5 & -0.288626343 & -0.4196497 & Yes \\
\hline row_42 & TFB2M & -0.295468986 & -0.40266645 & Yes \\
\hline row_43 & SUPV3L1 & -0.314724982 & -0.39104506 & Yes \\
\hline row_44 & AIMP2 & -0.356947273 & -0.38629338 & Yes \\
\hline row_45 & TCOF1 & -0.368350565 & -0.3653299 & Yes \\
\hline row_46 & LAS1L & -0.396683842 & -0.3479152 & Yes \\
\hline row_47 & SRM & -0.481136769 & -0.33877108 & Yes \\
\hline row_48 & UNG & -0.481530875 & -0.30541116 & Yes \\
\hline row_49 & PUS1 & -0.486822188 & -0.27321076 & Yes \\
\hline row_50 & WDR43 & -0.487907529 & -0.23950633 & Yes \\
\hline row_51 & MRTO4 & -0.540132403 & -0.21384856 & Yes \\
\hline row_52 & PA2G4 & -0.558176398 & -0.17846371 & Yes \\
\hline row_53 & PES1 & -0.568203509 & -0.14060867 & Yes \\
\hline row_54 & SLC29A2 & -0.696943164 & -0.113710806 & Yes \\
\hline row_55 & PLK4 & -0.704164445 & -0.06571903 & Yes \\
\hline row_56 & MCM4 & -0.753878117 & -0.020135336 & Yes \\
\hline row_57 & DUSP2 & -1.268203259 & 0.031331763 & Yes \\
\hline
\end{tabular}

GSEA, Gene set enrichment analysis; ES, enrichment score. 